\title{
Drug resistance related to aberrant glycosylation in colorectal cancer
}

\author{
Ninon Very ${ }^{1}$, Tony Lefebvre ${ }^{1}$ and Ikram El Yazidi-Belkoura ${ }^{1}$ \\ 'Unité de Glycobiologie Structurale et Fonctionnelle, UGSF-UMR 8576 CNRS, Université de Lille, Lille 59000, France \\ Correspondence to: Ikram El Yazidi-Belkoura, email: ikram.el-yazidi@univ-lille1.fr \\ Keywords: drug therapy resistance mechanisms, cancer chemotherapy, cancer-associated glycosylations, glycosyltrans- \\ ferases, colorectal cancer
}

Received: July 26, $2017 \quad$ Accepted: October 04, $2017 \quad$ Published: November 03, 2017

Copyright: Very et al. This is an open-access article distributed under the terms of the Creative Commons Attribution License 3.0 (CC BY 3.0), which permits unrestricted use, distribution, and reproduction in any medium, provided the original author and source are credited.

\begin{abstract}
Colorectal cancer (CRC) is the fourth leading cause of cancer-related deaths in the world. Drug resistance of tumour cells remains the main challenge toward curative treatments efficiency. Several epidemiologic studies link emergence and recurrence of this cancer to metabolic disorders. Glycosylation that modifies more than $\mathbf{8 0} \%$ of human proteins is one of the most widepread nutrient-sensitive posttranslational modifications. Aberrant glycosylation participates in the development and progression of cancer. Thus, some of these glycan changes like carbohydrate antigen CA 19-9 (sialyl Lewis a, sLea) or those found on carcinoembryonic antigen (CEA) are already used as clinical biomarkers to detect and monitor CRC. The current review highlights emerging evidences accumulated mainly during the last decade that establish the role played by altered glycosylations in CRC drug resistance mechanisms that induce resistance to apoptosis and activation of signaling pathways, alter drug absorption and metabolism, and led to stemness acquisition. Knowledge in this field of investigation could aid to the development of better therapeutic approaches with new predictive biomarkers and targets tied in with adapted diet.
\end{abstract}

\section{INTRODUCTION}

According to the World Health Organization (WHO) [1], colorectal cancer (CRC) is the third most common diagnosed cancer and the fourth cause of cancer-related death in the world (1,3 million new cases and 694000 deaths respectively in 2012). When diagnosed at an early stage, surgical resection is curative for most of the cases but for advanced stages a survival advantage is gained with the systemic administration of cytotoxic chemotherapy (5-year recurrence rates after primary surgery are nearly $10 \%$ and $36 \%$ for early (stages 1 and $2 \mathrm{~A}$ of the tumor/node/metastasis (TNM) classification of malignant tumors) and late (stages $2 \mathrm{~B}$ and 3) stage diseases respectively [2]). One established chemotherapy regimen for the treatment of advanced CRC (from stages 2B to 4) consists of the combination of 5-fluorouracil (5-FU)/leucovorin ( $\mathrm{LV}$, folinic acid) with oxaliplatin or irinotecan (camptothecin-11, CPT-11) [3]. Furthermore, targeted therapy based on the use of the monoclonal antibodies cetuximab and panitumumab that specifically bind the epidermal growth factor receptor (EGFR) and bevacizumab that neutralizes the vascular endothelial growth factor (VEGF) confers a benefit when administered in conjunction with chemotherapy [3]. However, the response rate is only about 57\% [4] and the 5 -year survival rate remains around $12,5 \%$ for patients with metastatic-stage disease [5]. The failure of treatments is primarily due to the development of drug resistance. In this context, much of current research is focused on the understanding of cancer resistance mechanisms and the identification of new predictive biomarkers and targets for drug therapy. We notice a renewed interest in the study of glycosylation since it was established that, compared to adjacent non-cancerous cells, CRC cells display glycosylation alterations which correlate with cancer progression and resistance to drug treatments. This review addresses the role of glycans in drug resistance mechanisms in CRC therapy. Particularly, the involvement of glycosyltransferases and related glycosylations in biological mechanisms controlling CRC development, progression and drug therapy resistance will be discussed. 


\section{THE MULTIPLE FACES OF GLYCOSYLATION IN MAMMALIAN CELLS}

Glycosylation is a group of post-translational modifications (PTM) in which carbohydrates are enzymatically linked to proteins, carbohydrates, lipids or any other kind of molecule [6]. Glycosylation represents one of the most abundant PTM since nearly $1-2 \%$ of human genome encode 236 different glycosyltransferases (CAZy database) and more than $80 \%$ of human proteins are glycosylated [7]. This modification can affect the folding, stability, subcellular localization, partners interaction and biological activity of a glycoprotein. Major protein glycosylations are classified according to the atom that links the glycan to the aglycone:nitrogen of the amide group of asparagine (Asn, $\mathrm{N}$ ) for $\mathrm{N}$-linked glycosylation ( $\mathrm{N}$-glycosylation) and oxygen of the hydroxyl group of serine (Ser, S) or threonine (Thr, T) for $O$-linked glycosylation ( $O$-glycosylation) (Figure 1).

\section{$N$-glycosylation}

In the $N$-linked glycosylation biosynthetic pathway, the preassembled precursor oligosaccharide GlcNAc2Man9Glc3 is co-translationally transferred from the dolichol pyrophosphate donor to an asparagine residue located in a NXS/T consensus sequence (where $\mathrm{X}$ is any amino-acid except proline (Pro, P)) of the nascent polypeptide in the lumen of the rough endoplasmic reticulum (ER) where $N$-glycosylation is necessary for protein folding and quality control [8]. This glycosylation is further processed and extended in the Golgi apparatus into oligomannose, hybrid or complex structures (Figure 1). N-acetylglucosaminyltransferases (GnT) are enzymes responsible for $\mathrm{N}$-glycan branching. Beta1,6-branched $\mathrm{N}$-glycans can be elongated with a poly-N-acetyllactosamine (poly-LacNAc) chain by the sequential addition of Gal $\beta 1,4-$ GlcNAc $\beta 1,3$ moieties by $\beta 1,4$-galactosyltransferases $(\beta 4 \mathrm{GalT})$ and $\beta 1,3-\mathrm{N}$-acetylglucosaminyltransferases (B3GnT). Alpha2,3-sialyltransferases (ST3GalT) and $\beta$-galactoside $\alpha 2,6$-sialyltransferase 1 (ST6GalT-1) mediate the $\alpha 2,3-$ and $\alpha 2,6$-sialylation of complex $N$-linked glycoproteins [9].

\section{Mucin-type $\boldsymbol{O}$-glycosylation}

Two of the most representative $O$-linked glycosylations are $O$-linked $\alpha$ - $\mathrm{N}$-acetylgalactosamine $(O$-GalNAc) commonly found in mucins and $O$-linked $\beta$-N-acetylglucosamine (O-GlcNAc). Mucin-type $O$-glycosylation is initiated by post-translationally transfer of N-acetylgalactosamine (GalNAc) through an $\alpha$-linkage in the Golgi [9]. Then, $O$-glycans are elongated with other carbohydrates to build various cores (Figure 1). Terminal structures of $N$-linked and $O$-linked mucintype glycans are often sialylated and fucosylated and can generate Lewis (Le) blood group antigen structures. Mucin-type $O$-glycosylation is initiated by a large family of Golgi polypeptide $\mathrm{N}$-acetylgalactosaminyltransferases (ppGalNAcT) [10] which transfer a GalNAc residue from uridine-5' -diphosphate-N-acetylglucosamine (UDPGalNAc) to serine or threonine residues to generate the Thomsen-nouvelle ( $\mathrm{Tn}$ ) antigen. Then, Tn antigen can be extended by sequential enzymatic reactions to form four core structures (Figure 1). Core $1 \beta 1,3-$ galactosyltransferase 1 (C1GalT-1) enzyme catalyzes the synthesis of core 1 (also named Thomsen-Friedenreich antigen, $\mathrm{T}$ antigen) by transferring a galactose (Gal) residue in a $\beta 1,3$ linkage to the Tn antigen, and core 2 $\beta 1,6-\mathrm{N}$-acetylglucosaminyltransferases (C2GnT) generate the core 2 by branching a GlcNAc residue in a $\beta 1,6$ linkage to core 1 . Both $\mathrm{Tn}$ and $\mathrm{T}$ antigens can be further sialylated into sialyl-Tn antigen (sTn) and sialyl-T antigen (sT) respectively by $\alpha$-GalNAc $\alpha 2,6$-sialyltransferase 1 (ST6GalNAcT-1) and ST3GalT-1 causing premature termination of chain elongation. As an alternative to core 1 , core $3 \beta 1,3-\mathrm{N}$-acetylglucosaminyltransferase (C3GnT) adds a GlcNAc residue in a $\beta 1,3$ linkage to the Tn antigen to form the core 3. Finally, like for core 1 , core 3 can be extended into core 4 by the core $4 \mathrm{~N}$-acetylglucosaminyltransferase $(\mathrm{C} 4 \mathrm{GnT})$ which transfers another GlcNAc residue in a $\beta 1,6$ linkage [9]. As $N$-glycosylation, mucin-type $O$-glycosylation takes place in the ER and/or Golgi apparatus biosyntheticsecretory pathway and targets secreted or membranebound proteins. Based on their cellular localization, mucins (MUC) are classified as secretory or membranebound glycoproteins. Membrane bound mucins (MUC1, MUC3-4, MUC12-17 and MUC20) are anchored to the apical membrane of epithelial cells by a transmembrane domain and are involved in signal transduction. In contrast, secretory mucins (MUC2, MUC5AC, MUC5B, MUC6-8 and MUC19) lack the transmembrane domain and are secreted into the extracellular space to compose a viscoelastic mucus gel, a protective and lubricative molecular barrier [11].

\section{Lewis-type antigen glycosylation}

Depending on the core disaccharide linkage on $\mathrm{N}$ or $O$-linked glycoproteins, terminal Lewis blood group antigens are classified as either type 1 (Gal $\beta 1,3-\mathrm{GlcNAc})$ or type $2(\mathrm{Gal} \beta 1,4-\mathrm{GlcNAc})$ structures $[9,12]$. Alpha1,2fucosyltransferases ( $\alpha 2 \mathrm{FucT}$ ) 1 and 2 (FucT-1 and FucT-2) transfer a fucose (Fuc) in an $\alpha 1,2$ linkage to type 1 and type 2 structures to produce respectively $\mathrm{H} 1$ - and $\mathrm{H} 2$-type determinants (Figure 1). H1- and H2-type structures can be further converted into Lewis b (Leb) and Lewis y (Ley) di-fucosylated antigens respectively by fucosylation in an $\alpha 1,4$ or an $\alpha 1,3$ linkage by $\alpha 1,3 / 4$-fucosyltransferases ( $\alpha 3 / 4$ FucT) FucT-3-7 and FucT-9 [9, 12]. Lewis a (Lea) and Lewis $\mathrm{x}$ (Lex) mono-fucosylated antigens are 
positional isomers of respectively Leb and Ley antigens but are not fucosylated in $\alpha 1,2$. Moreover, $\alpha 1,4-$ and $\alpha 1,3$-fucosylation of Lea and Lex can be forewent by the addition of $\alpha 2,3$-sialic acid by ST3GalT-3-4 and ST3GalT-6 to form sialyl Lea (sLea) and sialyl Lex (sLex) $[9,12]$.

\section{O-GIcNAcylation}

Contrary to $N$ - and mucin-type $O$-glycosylations found in secreted and membrane-anchored glycoproteins, $O$-GlcNAcylation occurs exclusively on cytoplasmic, nuclear and mitochondrial proteins [13]. O-GlcNAcylation is also different from all other classical glycosylations since it consists in the reversible addition of a single GlcNAc residue (Figure 1). It is a dynamic PTM that implies addition and removal of GlcNAc residues by a unique couple of antagonist enzymes, $O$-GlcNAc transferase (OGT) and $O$-GlcNAcase (OGA) respectively. OGT transfers a single GlcNAc from uridine-5'diphosphate-N-acetylglucosamine (UDP-GlcNAc) via a $\beta 1$-linkage to hydroxyl group of serine or threonine residues of intracellular proteins involved in a plethora of biological processes such as cell signaling, transcription or cell cycle [13-16].

\section{FROM THE METABOLISM SHIFT TO THE ALTERATIONS OF GLYCOSYLATIONS IN CANCER CELLS}

\section{Warburg effect and hexosamine biosynthetic pathway}

One of the key hallmarks of cancer cells is the Warburg effect, an adaptive metabolic shift from oxidative phosphorylation to aerobic glycolysis $[17,18]$. This adaptive

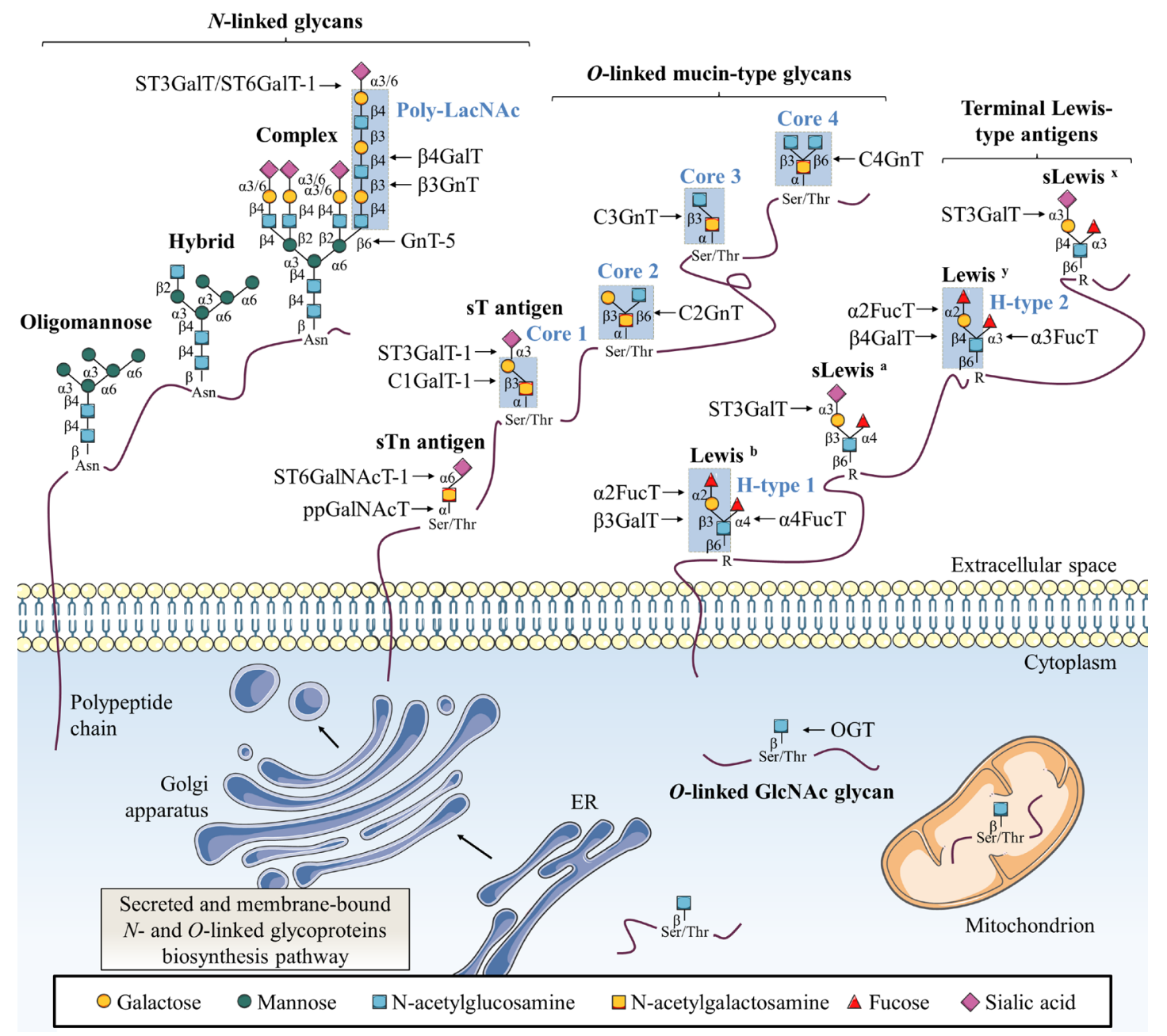

Figure 1: Classical glycosylation types found on mammalian proteins. This figure depicts common $N$-linked and $O$-linked glycoprotein structures as well as terminal Lewis antigens structures. The key glycosyltransferases responsible for the addition of specific glycans are also indicated. Secreted and membrane-bound glycoproteins exhibit $N$-glycans with $\beta$-GlcNAc linked to Asn as oligomannose, complex or hybrid forms. $O$-glycans are linked through $\alpha$-GalNAc to Ser/Thr with various core structures and extensions. Terminal structures of $N$-linked and $O$-linked glycans are often sialylated and fucosylated to generate Lewis-type antigen glycosylation. Single $\beta$ - $O$ GlcNAc is found on many cytosolic, nuclear and mitochondrial proteins. 
metabolic is thought to provide an evolutionary advantage to cancer cells by providing both increase bioenergetics and biosynthesis. Warburg effect is characterized by an increase of glucose (Glc) and glutamine (Gln) consumption. Glucose and glutamine are the most abundant extracellular nutrients which support the growth and proliferation of cancer cells by contributing to energy production (glycolysis via glucose and Krebs cycle via glutaminolysis) and de novo biosynthesis of macromolecules (lipids, nucleic acids and proteins) $[19,20]$. It is possible to take advantage of the increased cancer cells demand to detect primary and metastatic tumor sites by monitoring the incorporation of the glucose radioanalogue 2-deoxy-2-(18F)fluoroglucose ([18F] FDG]) with positron emission tomography (PET) scan [21]. Elevated glucose uptake takes an active part in the increase of the pentose phosphate pathway (PPP) to produce reduced nicotinamide adenine dinucleotide phosphate (NADPH2) needed for fatty acid synthesis and pentoses incorporated in nucleic acids, and the hexosamine biosynthetic pathway (HBP) that generates UDP-GlcNAc (Figure 2). Approximately 2-3\% of the glucose entering the cell are directed to the HBP [22]. Glutamine takes also an active part in HBP as the first and rate limiting step of this pathway is catalyzed by glutamine:fructose-6-phosphate amidotransferase (GFAT) which converts fructose-6phosphate (Fru-6-P) to glucosamine-6-phosphate (GlcN-6-P) using glutamine as the amine group donor [23]. Through a subset of enzymatic reactions, GlcN-6-P is then converted to the nucleotide sugar UDP-GlcNAc, the end-product of HBP. UDP-GlcNAc is considered as a nutritional state sensor of the cell because it integrates glucose, amino acids, fatty acids and nucleotides metabolisms. UDP-GlcNAc can undergo epimerization to generate UDP-GalNAc used in the ER and Golgi apparatus and cytidine-5'-monophospho$\mathrm{N}$-acetylneuraminic acid (CMP-Neu5Ac), the donor of Neu5Ac, used in the Golgi apparatus for terminal glycosylation of cell membrane and secreted glycoproteins (Figure 2).

\section{Loss of glycosylation control in cancer cells}

Another well-established cancer phenotypic marker is altered glycosylation that underlies tumor growth and malignancy. Specific aberrant glycosylations are associated to CRC. These glycosylation abnormalities are caused by increased abundance and availability of nucleotide sugars [24-26] and altered expression or activity of the corresponding glycosyltransferases [27]. Specifically, overexpression of OGT is correlated with overall increased $O$-GlcNAcylation of intracellular proteins [28]. In the other hand, overexpression of GnT5 [29] and $\beta 3 \mathrm{GnT}[30]$ is responsible for an increase of branched- $N$-glycans with respectively GlcNAc residue and poly-LacNAc chain. Truncated mucin-type $O$-glycans such as $\mathrm{T}$ and $\mathrm{Tn}$ antigens result from the overexpression of the first-step biosynthesis enzymes ppGalNAcT combined to down-expression of $O$-glycan extension enzymes C2GnT, C3GnT and C4GnT [31-33]. Increased activity of $\alpha 2$ FucT participate also in the synthesis of Leb and Ley oncofetal antigens [34-37]. These antigens are expressed in colon during fetal life, gradually decrease in adult life to be mostly restricted to the proximal colon and are re-expressed in distal colon and rectal carcinomas $[34,37]$. Finally, the most-widely aberrant glycosylation associated with CRC is an increase of global sialylation. Overexpression of sialyltransferases such as ST6GalT-1, ST3GalT and ST6GalNAcT-1 is involved in aberrant glycan structures including $\alpha 2,6$-sialylated $N$-glycans, sTn, sLea (also known as carbohydrate antigen 19-9, CA 19-9) and sLex (Figure 2). SLea and carcinoembryonic antigen (CEA) are widely used as serum glycoprotein biomarkers to monitor and detect recurrence of CRC even if they show low specificity and sensitivity in initial diagnosis [38]. Recently, targeted next-generation sequencing defined the mutational landscapes of glycosylationassociated genes in CRC. Notably, authors identified somatic mutations in glycosyltransferase genes encoding $\beta 3 \mathrm{GnT}-2, \beta 4 \mathrm{GalT}-2$ and ST6GalNAcT-2 involved in the synthesis of poly-LacNAc chains on $N$ - and $O$-glycans for the two former, and in the sialylation-mediated termination chain elongation of $O$-glycan core 1 and 3 structures for the latter. Functional studies showed that these mutations are responsible for impairment of localization, enzymatic activity and PTM pattern [39].

In addition to have a major role in the CRC development and progression, some of these aberrant glycosylations have been correlated to drug resistance by interfering with metabolism, absorption, antiproliferative and anti-apoptotic effects of the drugs. This will be discussed in detail in the next sections by type of glycosylation.

\section{GLYCOSYLATION ALTERATIONS IN COLORECTAL CANCER CELLS AND RESISTANCE TO DRUG THERAPY}

\section{$\mathrm{N}$-glycosylation alterations in colorectal cancer: a cause of drug resistance}

\section{Disturbing $N$-glycosylation profile impacts the response to chemotherapy}

The use of glycosylation inhibitors demonstrated the importance of $N$-glycosylation in chemoresistance mechanisms. First, swainsonine, a potent inhibitor of $\alpha$-mannosidase 2 that is essential for the production of complex-type $N$-glycans, increased 5-FU sensitivity in all induced-resistant cell lines established from colon 26, a mouse cancer colorectal cell line, but not in its parental one [40]. The authors observed that $N$-glycan profiles of both the resistant and parental cells were changed by swainsonine treatment and showed that alterations in the 
$N$-glycan structure affected mechanisms of 5-FU resistance by up-regulating thymidylate synthetase (TS) expression and down-regulating orotic acid phosphoribosyltransferase (OPRT) expression at the transcriptional level (Figure 3). However, the underlying mechanism correlating $N$-glycan structures profile and 5-FU metabolizing-enzymes expression is not yet elucidated. Drug-metabolizing enzymes play an important role in reducing the intracellular accumulation of drugs. Their expression can therefore either potentiate or reduce the drugs toxicity, and variations in both the anabolic and catabolic pathways can lead to drug resistance. Increased expression of TS, a key enzyme in pyrimidine metabolism and the major target of 5-FU, and decreased expression of the anabolic enzyme OPRT have already been associated with 5-FU resistance [41]. Secondly, ATP-binding cassette (ABC) sub-family

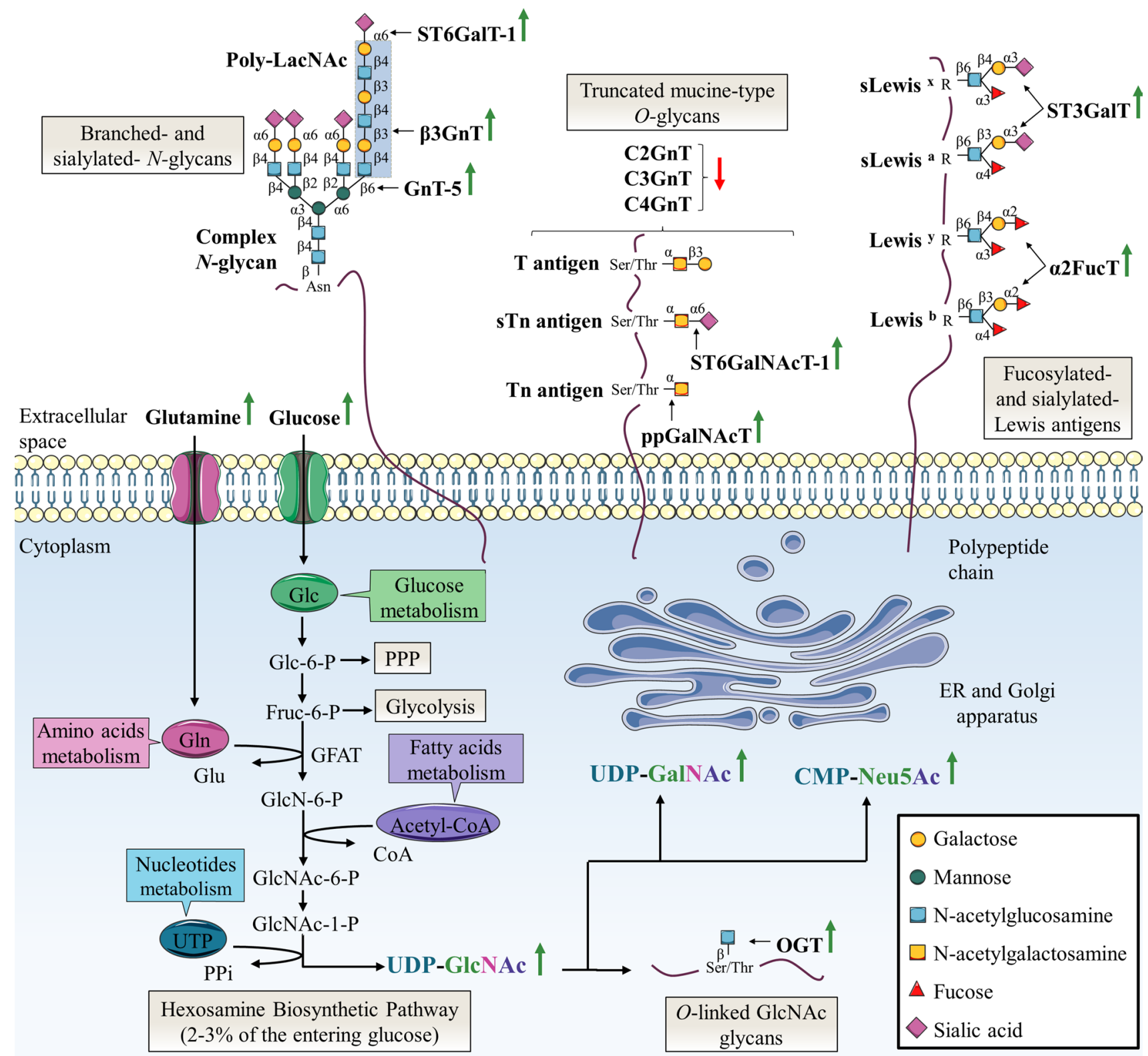

Figure 2: Specific alterations of glycosylation in colorectal cancer. The HBP pathway produces the nucleotide sugar UDPGlcNAc in a nutrient-dependent manner. UDP-GlcNAc is critical for most kinds of glycosylation including $N$-glycosylation, $O$-GalNAcbased glycosylation and $O$-GlcNAcylation. In this sense, glycan structures are modified according to the metabolic status of the cell. The abnormal glycosylation which occurs in cancer cells can be attributed to abundance and availability of nucleotide sugars, acceptor substrates or cofactors in the same way as altered expression or activity, or mislocalization of glycosyltransferases. The most frequent abnormal glycosylations observed in CRC are increased branched- and sialylated- $N$-glycans, truncated mucin-type $O$-glycans, increased fucosylation and sialylation of Lewis antigens and increased $O$-GlcNAcylation. Green and red arrows indicate respectively increased and decreased availability of nutrients and nucleotide sugars, or expression or activity of glycosyltransferases in CRC. Acetyl-coA: acetyl-coenzyme A; Fru-6-P: fructose-6-phosphate; Glc-6-P: glucose-6-phosphate; GlcN-6-P: glucosamine-6-phosphate; GlcNAc-6-P: N-acetylglucosamine-6phosphate; GlcNAc-1-P: N-acetylglucosamine-1-phosphate; Glu: glutamic acid; UTP: uridine triphosphate; PPi: inorganic pyrophosphate. 
G member 2 (ABCG2) is an $N$-linked glycosylated transporter responsible for efflux of the active metabolite of irinotecan 7-ethyl-10-hydroxycamptothecin (SN-38) (Figure 3). Overexpression of this efflux pump in cancer cells gives them also the ability to reduce chemotherapy intracellular concentration [41, 42]. Disruption of the early steps of the dolichol pyrophosphate precursor biosynthesis by treatment of Flp-ln-293 embryonic kidney cells with tunicamycin decreases stability of ABCG2 and reduces cell resistance to SN-38 [43] (Figure 4A). In the same way, Santos et al. demonstrated an increased antitumor activity by combined administration of swainsonine and cisplatin in vivo [44]. Authors suggested that swainsonine may interfere with ABCB1 activity, a broad-spectrum multidrug efflux pump whose activity is dependent on $N$-glycosylation. Based on the aforementioned data, $\mathrm{N}$-glycosylation can alter intracellular drug accumulation by reducing drug anabolism and increasing drug export. Targeting $N$-glycosylation may improve cancer chemotherapy and reduce drug resistance.

\section{Beta1,6-GlcNAc bearing $N$-glycans implication in drug resistance}

Increased expression of $\beta 1,6-\mathrm{GlcNAc}$ bearing $\mathrm{N}$-glycans is a frequent cancer-associated modification due to abnormal expression of GnT-5. In the Golgi apparatus, GnT-5 catalyzes the transfer of GlcNAc to the trimannosyl core of $\mathrm{N}$-glycan to produce tri or tetra-antennary complex glycans (Figure 1). GnT-5 expression is increased in different cancers [45, 46] including colon cancer [29] (Figure 2). In CRC, GnT-5 expression is associated with metastasis likely through glycosylation of the tissue inhibitor of metalloproteinase-1 (TIMP-1). Aberrant $\mathrm{N}$-glycosylation of TIMP-1 affects its binding properties with matrix metalloproteinases (MMP) increasing cancer cell invasiveness [47].

The contribution of $\beta 1,6$-branched $N$-glycans in cancer angiogenesis was reinforced by the observation that vasculature of anti-VEGF resistant mice tumors presented high levels of $\beta 1,6$-GlcNAc branched $N$-glycans. In this model, GnT-5 knockdown increased efficacy of anti-VEGF treatment by modulating the interaction of some $\beta$-galactoside-binding lectins galectins with cell surface glycoproteins. Galectin-1 (Gal-1) is able to bind complex-type $N$-glycans on endothelial cell VEGF receptor 2 (VEGFR-2) and to activate an angiogenic signaling pathway in the absence of VEGF-A ligand. In fact, binding of Gal-1 resulted in VEGFR-2 clustering into membrane microdomains and increased surface retention. It was suggested that loss of $\beta 1,6-\mathrm{GlcNAc}$ $\mathrm{N}$-glycan branching prevents Gal-1 binding to endothelial cells [48] (Figure 4B; Table 1). In this way, extrinsic properties of tumor-associated microenvironment can influence directly the drug response in cancer. Activation of the angiogenic pathway by the GnT-5 mediated $\mathrm{N}$-glycosylation of VEGFR-2 in the absence of ligand binding could be responsible, in part, of failure of antiVEGF treatment. To circumvent this resistance, Croci et al. proposed targeting glycosylation-dependent galectinreceptor interactions and validated therapeutic efficiency of an anti-Gal-1 neutralizing monoclonal antibody [48]. Alternative therapeutic strategies targeting galectin-glycan interactions include $\beta$-galactose ligands, talose-based ligands and mimicking glycans [49]. In the other hand, we can also consider blocking the VEGF-VEGFR-2 signaling at a downstream level for example with receptor tyrosine kinases (RTK) inhibitors (TKI). A second-generation of these agents with higher specificity for VEGFR inhibition and favorable toxicity profiles are currently under clinical evaluation in metastatic CRC [50].

\section{Poly-LacNAc chain bearing $N$-glycans implication in drug resistance}

Among the $\beta 3 \mathrm{GnT}$ family, $\beta 3 \mathrm{GnT}-8$ is the most recently identified enzyme involved in the biosynthesis of poly-LacNAc chain on tetra-antennary $N$-glycans [30] (Figure 1). The $\beta 3 \mathrm{GnT}-8$ transcript level is almost undetectable in normal colon tissues while it is increased in cancer tissues [30] (Figure 2). The $\beta 3 \mathrm{GnT}-8$ expression is also correlated with metastatic potential of CRC cells notably by targeting cluster of differentiation 147 (CD147), also known as extracellular matrix metalloproteinase inducer (EMMPRIN) [51]. High $N$-glycosylated CD147 (HG-CD147), the active glycoform, is enriched on cancer cell surface and promotes production of secreted MMP in tumor cells themselves and in adjacent stromal cells [52].

$\mathrm{Ni}$ et al. showed that $\beta 3 \mathrm{GnT}-8$ overexpression and silencing respectively increases and decreases levels of HG-CD147 in LoVo metastatic colon cancer cell line revealing that HG-CD147 glycans consists of $\beta 1,6$-branched poly-LacNAc chains [51]. In parallel, $\beta 3 \mathrm{GnT}-8$ is overexpressed in 5 -FU resistant colon cell line SW620 compared to parental sensitive cells and knockdown of $\beta 3 \mathrm{GnT}-8$ resensitizes cells to 5-FUmediated apoptosis. However, the underlying mechanism leading to 5-FU resistance is unknown [53]. Recent findings suggest that glycosylated CD147 plays an essential role in multidrug resistance mechanism. CD147 is associated with CRC stem cells (CSC) [54], a minor cell population characterized by a slow rate of proliferation, an undifferentiated phenotype, a self-renewal potential and the capacity to generate differentiated progeny [55]. The longevity of CSC renders them more vulnerable to accumulate DNA damages and epigenetic alterations that may promote the proliferation of heterogeneous and aggressive cell phenotypes [55, 56]. Furthermore, some CSC can be found in hypoxic tumor niches distant from functional blood vessels which favor the maintenance of their undifferentiated state and exposed them to suboptimal drug concentrations [57]. In this sense, CSC appear to be more resistant towards chemotherapy than more proliferative progenitors coexisting within the tumor. It 
was shown that CD147 promotes epithelial-mesenchymal transition (EMT) [58], a trans-differentiation process by which epithelial-polarized cells acquire a mesenchymal phenotype and generate some cancer cells with stem-like cell properties [59, 60] (Figure 4D). Silencing CD147 sensitized cells to chemotherapeutic reagents including 5-FU [58], oxaliplatin [61] gemcitabine, cisplatin and docetaxel [54]. We may hypothesize that stimulation of the EMT by HG-CD147 leads to the formation of a pool of slowly-proliferative chemoresistant CSC. The therapy actually envisaged to inhibit this resistance mechanism is to specifically recognize and eliminate CSC $[62,63]$. Thus, HG-CD147 may constitute a potential chemoresistance biomarker useful for identifying and therapeutically targeting CSC.

\section{$N$-glycosylation alterations in colorectal cancer: a cause of drug resistance}

Increased terminal sialylation of branched $N$-glycans is a common feature of cancer. ST6GalT-1 is a Golgi enzyme that catalyzes the transfer of the sialic acid Neu5Ac to the terminal galactose of $N$-glycans (Figure 1). ST6GalT-1 expression and global $\alpha 2,6$-sialylation are up-regulated in CRC [64] (Figure 2) and in many other cancers [65]. Ras oncogene that transcriptionally drives ST6GalT-1 expression is mutated in 50\% of CRC leading to the glycosyltransferase expression increase
[66]. ST6GalT-1 expression is positively correlated with metastatic potential of colon cancer cells [67, 68], CSC markers expression [69] and poor prognostic [70]. ST6GalT-1 enhances migration and invasion properties of tumor cells. On the one hand, the enzyme activates the phosphoinositide 3-kinase (PI3K)/Akt mitogenic signaling pathway in vitro [71] and in vivo [72] by targeting integrins and potentially some RTK. On the other hand, forced $\alpha 2,6$-sialylation of $\beta 1$ integrin subunit enhances its activity and subsequent cell migration by improving extracellular matrix (ECM)/cytoskeleton interactions [68].

Accumulating studies showed that ST6GalT-1 displays anti-apoptotic activities. First, it has been reported that ST6GalT-1 regulates apoptosis signaling in response to galectins [73]. In this way, overexpression of ST6GalT-1 and $\alpha 2,6$-sialylation of $\beta 1$ integrins prevents galectin-3 (Gal-3) binding and pro-apoptotic activity in SW48 colon cancer cells (Figure 4C). Intriguingly, mice tumor vessels exhibiting high levels of $\alpha 2,6$-sialylation were more sensitive to anti-VEGF whereas ST6GalT-1 knockout mice lacking this modification resisted to anti-VEGF therapy [48]. Contrary to $\beta 1,6$-branched $N$-glycans, loss of $\alpha 2,6-$ sialylation may activate VEGF-like pathway by unmasking Gal-1-specific binding sites on ligands such as VEGFR-2 [48] (Table 1). Next to the galectin-mediating pathway, a2,6-sialylation of EGFR decreased its EGF-mediated
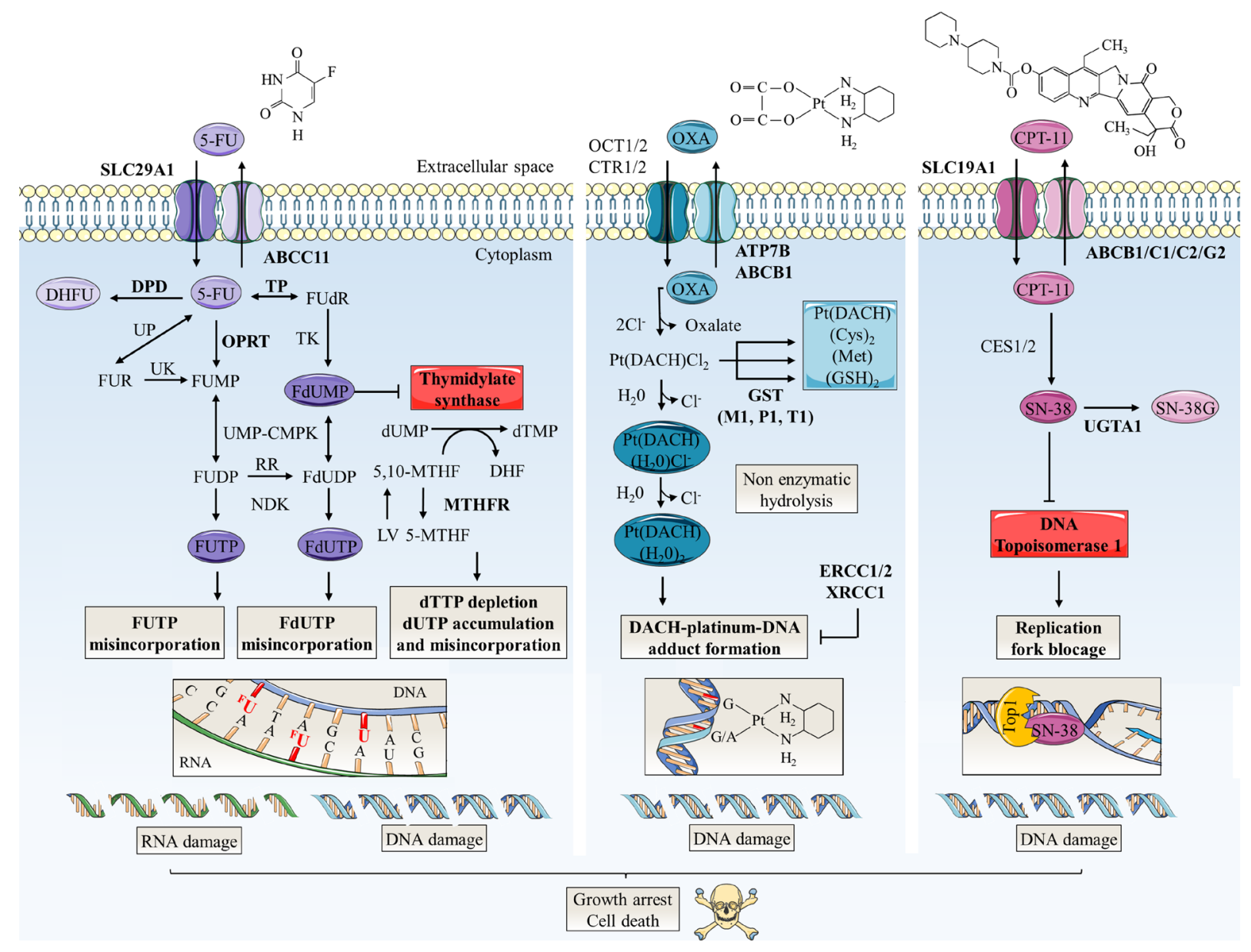
Figure 3: Schematic representation of mechanisms of action and resistance biomarkers in main colorectal cancer chemotherapies. 5-FU, oxaliplatin (OXA) and CPT-11 are the principal anti-colorectal cancer drugs. Arrow-headed lines indicate metabolite chemical conversion whereas bar-headed lines represent inhibition of chemical process (OXA pathway) or enzymes (5-FU and CPT-11 pathways). The anabolic pathways are dark-colored and the catabolic pathways are light-colored. Some of therapy resistance biomarkers are indicated in bold. 5-FU penetrates in tumor cell by nucleoside solute carrier (SLC) transporters such as SLC29A1. Then, 5-FU is converted to three main active metabolites: FdUMP, fluorodeoxyuridine triphosphate (FdUTP) and fluorouridine triphosphate (FUTP) which acts as antimetabolites and pyrimidine analogues. FdUMP decreases the biosynthesis of pyrimidine nucleotides by inhibiting TS, the enzyme that catalyzes the rate limiting step in DNA synthesis by catalysing the reductive methylation of deoxyuridine monophosphate (dUMP) to deoxythymidine monophosphate (dTMP) using 5,10-methylenetetrahydrofolate (5,10-MTHF) as the methyl donor. By this way, FdUMP inhibits DNA synthesis and repair leading to DNA strand breakage and cell death notably by induction of apoptosis. 5-FU is also incorporated into DNA (via FdUTP) or RNA (via FUTP), leading to other cytotoxic actions including DNA fragmentation and decrease in protein synthesis. LV expands the intracellular pool of 5,10-MTHF and increases the toxicity of 5-FU. DPD mediates the conversion of 5-FU to non-active dihydrofluorouracil (DHFU). 5-FU catabolism also includes efflux of metabolites by ABC transporters such as ABCC11. TS and OPRT over-expressions are major molecular mechanism of 5-FU resistance. OXA, a third generation of alkylating platinum agent, is transported mainly by organic cation (OCT1/2) and copper (CTR1/2) transporters. On the contrary, P-type ATPase (ATP7A/B) transporters and ABC transporters promote its efflux. Inside the cell, displacement of the labile oxalate and non-enzymatic hydrolysis promotes the conversion of OXA in active metabolites such as monoaquo-1,2-diaminocyclohexane (DACH) platinum and diaquo-DACH platinum. These products alkylate DNA leading to G/G or G/A intra-strand crosslinks which, if not repaired, will block both DNA replication and transcription leading to apoptosis. Hydrophobicity and bulkiness of the DACH ring prevents the MMR proteins from binding to OXA. Excision repair cross-complementation 1 and 2 (ERCC1/2) and X-ray repair cross complementing 1 (XRCC1) are involved in repair of DNA adducts. Cellular detoxification processes include metabolites targeting for excretion by conjugation of aquated compounds to cysteine (Cys), methionine (Met) or GSH. In particular, conjugation of GSH is catalysed by GST (-mu GSTM1, -pi GSTP1 and -theta GSTT1). CPT-11 is transported by SLC transporters such as SLC19A1. Inside the cell, CPT-11 is converted into the active SN38 by carboxylesterases 1 and 2 (CES1/2). SN-38 binds and stabilizes its target DNA Top1 responsible for supercoiled DNA relaxation during replication and transcription. SN-38 inhibits the relegation step and the collision of the SN-38/Top1 complex with the moving DNA replication fork leads to irreversible arrest of the replication fork and double DNA stranded breaks. This damage causes cell-cycle arrest and apoptosis. CPT-11 resistance mechanisms include SN-38 glucuronidation in inactive SN-38 glucuronide (SN-38G) by uridine diphosphate glucuronosyltransferase 1 polypeptide $\mathrm{A} 1$ (UGT1A1) and overexpression of $\mathrm{ABC}$ transmembrane transporters (ABCB1, $\mathrm{ABCC} 1, \mathrm{ABCC} 2$ and $\mathrm{ABCG} 2)$ responsible for efflux of SN-38. 5-MTHF: 5-methyltetrahydrofolate; Cl-: chlorine; DHF: dihydrofolate; dTTP: deoxythymidine triphosphate; dUTP: deoxyuridine triphosphate; FdUDP: fluorodeoxyuridine diphosphate; FU: fluorouracil; FUDP: fluorouridine diphosphate; FUMP: fluorouridine monophosphate; FUR: fluorouridine; MTHFR: methylene tetrahydrofolate reductase; NDK: nucleoside-diphosphate kinase; $\mathrm{Pt}(\mathrm{DACH})(\mathrm{Cl} 2)$ : dichloro-DACH platinum; $\mathrm{Pt}(\mathrm{DACH})(\mathrm{H} 20) 2$ : diaquo-DACH platinum; $\mathrm{Pt}(\mathrm{DACH})$ (H20)Cl-: monoaquo-DACH platinum; RR: ribonucleotide reductase; UK: uridine kinase; UMP-CMPK: uridine monophosphate/cytidine monophosphate kinase; UP: uridine phosphorylase.

tyrosine phosphorylation activity and promotes resistance to gefitinib, an EGFR-targeted TKI (Figure 4B; Table 1). The cytotoxic effect of gefitinib is respectively decreased and increased in CRC cell lines overexpressing or deficient in ST6GalT-1 [67]. Alpha2,6-sialylation of EGFR could prevent its dimerization and activation as it was shown that sialidase increased EGFR dimer formation upon EGF treatment in lung cancer cells [74]. Interestingly, EGFR gene copy number is strongly positively-associated with sensitivity to EGFR TKI in CRC [75, 76]. Together, these results indicate that active EGFR is necessary to effective response to TKI. Due to heterogeneous scoring systems and technical obstacles, estimation of EGFR gene copy number as EGFR TKI predictive biomarker is still unpractical in clinical practice [76]. Alpha2,6-sialylation of EGFR could be envisaged as another potential predictive biomarker. In addition, $\alpha 2,6$-sialylation could inhibit apoptosis initiated by the Fas ligand (FasL) binding to Fas cell death receptor (FasR) [77]. In fact, ST6GalT-1 mediated $\alpha 2,6$-sialylation of FasR prevents the formation of active death inducing signaling complex (DISC) by blocking the binding of the Fas-associated adaptor protein (FADD) to the FasR death domain and inhibits the internalization of stimulated FasR necessary for induction of apoptosis (Figure 4C; Table
1). It was similarly reported that ST6GalT-1-mediated sialylation of the tumor necrosis factor receptor 1 (TNFR1) protects macrophages against TNF- $\alpha$-induced apoptosis [78]. Cytotoxic effects of anti-cancer drugs are generally mediated by the activation of intrinsic and extrinsic proapoptotic cascades in response to DNA damages or other cellular injuries [79]. Anti-CRC drugs activate the extrinsic apoptotic pathway via up-regulation of expression and/or activation of death-receptors and downstream actors [80]. Evasion of apoptosis mediated by increased expression of anti-apoptotic proteins and decreased expression of pro-apoptotic proteins contributes to drug resistance [79]. Some targeted agents are currently evaluated to restore the impaired apoptotic signals in CRC. These include death receptor ligands or agonists, B-cell lymphoma 2 (Bcl-2) antagonists, Bcl-2 homology 3 (BH3) mimetics or inhibitors of apoptosis (IAP) antagonists in monotherapy or in combination with standard chemotherapy regimens $[80,81]$. Detection of aberrant $N$-glycosylation on inactive death receptors could allow choosing an appropriate therapeutic strategy by favoring targeted therapies against downstream effectors in the extrinsic apoptotic pathway such as IAP. Finally, ST6GalT-1 expression is restricted to stem cell compartment at the base of colonic crypts in normal 
Table 1: Glycosylations involved in anti-cancer drug response of colorectal cancer

\begin{tabular}{|c|c|c|c|c|c|c|}
\hline Types of glycosylation & $\begin{array}{c}\text { Glycosyl-transferases } \\
\text { involved }\end{array}$ & Targets & Functional roles & Drug responses & Cell types/tissues & References \\
\hline $\begin{array}{l}\beta 1,6 \quad \text { branching of } \\
N \text {-glycans }\end{array}$ & GnT-5 & VEGFR-2 & $\begin{array}{l}\text { Promotes pro-angiogenic } \\
\text { Gal-1 binding }\end{array}$ & $\begin{array}{l}\text { Decreases anti-VEGF } \\
\text { antibody sensibility }\end{array}$ & $\begin{array}{l}\text { HUVEC1 cells and } \\
\text { transgenic mice models }\end{array}$ & [48] \\
\hline $\begin{array}{l}\text { Poly-LacNAc chain on } \\
N \text {-glycans }\end{array}$ & $\beta 3 \mathrm{GnT}-8$ & - & - & Decreases 5-FU sensitivity & SW6202 cells & [53] \\
\hline \multirow[t]{5}{*}{$\begin{array}{l}\alpha 2,6 \text {-linked sialylation of } \\
N \text {-glycans }\end{array}$} & ST6GalT-1 & VEGFR-2 & $\begin{array}{l}\text { Prevents pro-angiogenic } \\
\text { Gal-1 binding }\end{array}$ & $\begin{array}{l}\text { Increases anti-VEGF } \\
\text { antibody sensitivity }\end{array}$ & $\begin{array}{l}\text { HUVEC1 cells and } \\
\text { transgenic mice models }\end{array}$ & [48] \\
\hline & & $\beta 1$ integrin & $\begin{array}{l}\text { Prevents pro-apoptotic } \\
\text { Gal-3 binding }\end{array}$ & Decreases Gal-3 sensitivity & SW482 cells & [73] \\
\hline & & FasR & $\begin{array}{l}\text { Prevents formation of } \\
\text { active DISC }\end{array}$ & Decreases FasL sensitivity & HD32 and SW482 cells & {$[77]$} \\
\hline & & EGFR & $\begin{array}{l}\text { Decreases EGF-mediated } \\
\text { phosphorylation and } \\
\text { activation }\end{array}$ & $\begin{array}{c}\text { Decreases gefitinib } \\
\text { sensitivity }\end{array}$ & $\begin{array}{l}\text { SW4802, HT-292, HCT- } \\
1162 \text { and SW482 cells }\end{array}$ & {$[67]$} \\
\hline & & - & $\begin{array}{l}\text { Increases cancer stem cells } \\
\text { population }\end{array}$ & $\begin{array}{c}\text { Decreases irinotecan } \\
\text { sensitivity }\end{array}$ & HD32 and SW9482 cells & [69] \\
\hline \multirow{2}{*}{$\begin{array}{l}\text { Mucin-type } \\
O \text {-glycosylation }\end{array}$} & ppGalNAcT-3 & - & - & Increases TRAIL sensitivity & DLD-12 and C1702 cells & [113] \\
\hline & ppGalNAcT-14 & - & - & $\begin{array}{l}\text { "TT" genotype negatively } \\
\text { correlated with oxaliplatin } \\
\text { sensitivity }\end{array}$ & $\begin{array}{l}\text { Patients with stage III } \\
\text { colorectal cancer (CRC) }\end{array}$ & {$[115]$} \\
\hline \multirow{6}{*}{$\begin{array}{l}\text { Lewis blood group antigen } \\
\text { structures }\end{array}$} & FucT-1/FucT-2 & - & - & Decreases 5-FU sensitivity & REG3 and PRO3 cells & {$[122]$} \\
\hline & & & & & REG3 and PRO3 cells & {$[123]$} \\
\hline & & & & & DLD-12 cells & [124] \\
\hline & FucT-3 & - & - & $\begin{array}{l}\text { Expression of FUT-3 } \\
\text { positively correlates with } \\
\text { TRAIL sensitivity }\end{array}$ & CRC cell lines 2 panel & [113] \\
\hline & FucT-6 & - & $\begin{array}{l}\text { Increases DISC activation } \\
\text { of capase- } 8\end{array}$ & Increases TRAIL sensitivity & DLD-12 and C1702 cells & [113] \\
\hline & - & - & - & $\begin{array}{c}\text { Expression of sLex } \\
\text { negatively correlates with } \\
\text { irinotecan/5-FU/leucovorin } \\
\text { therapy sensitivity }\end{array}$ & $\begin{array}{l}\text { Patients with advanced or } \\
\text { recurrent CRC }\end{array}$ & [131] \\
\hline \multirow[t]{2}{*}{$O$-GlcNAcylation } & OGT & - & $\begin{array}{l}\text { Interacts with TET1 and } \\
\text { SET1/COMPASS complex } \\
\text { on promoter region of Nrf2 }\end{array}$ & Decreases 5-FU sensitivity & SNUC52 cells & [161] \\
\hline & & - & - & $\begin{array}{l}\text { OGT expression negatively } \\
\text { correlates with FdUMP } \\
\text { sensitivity }\end{array}$ & NCI-602 cells & {$[165]$} \\
\hline
\end{tabular}

- : not defined; 1: human umbilical vein endothelial cells; 2: human colorectal carcinoma cells; 3 : rat colorectal carcinoma cells.

colon tissue and correlated with aldehyde dehydrogenase 1 (ALDH1) stem cell marker [69]. In colon carcinoma cell lines, ST6GalT-1 expression also correlates with CD133/ ALDH1 positive CSC [69]. Conversely, knockdown of ST6GalT-1 decreases the proportion of CSC. Irinotecan resistant cells show an increase in expression and activity of ST6GalT-1 and a greater proportion of CSC compared to parental sensitive cells (Figure 4D). In this study, the authors regard ST6GalT-1 as a CSC potential marker.

\section{Mucin-type $O$-glycosylation profile alterations in colorectal cancer: a barrier to drug therapy}

\section{Truncated mucin-type $\boldsymbol{O}$-glycosylation in CRC}

High density of truncated mucins is another common tumor-associated carbohydrate modification. Compared to normal colon mucins which exhibit the four core structures (Figure 1) and mainly core-3 based $O$-glycans [82], during malignant transformation mucins present a dramatic decrease of core 3 and core
4 and an increase of $\mathrm{T}$ antigen. These modifications result from the deregulation of the glycosyltransferases involved in the building of the different structures [31-33] (Figure 2). The Sda blood group epitope bound to $O$-glycans core- 3 is mostly expressed in healthy colorectal tissue but not in $\mathrm{CRC}$ cells. Accordingly, the expression of $\beta 1,4-\mathrm{N}$-acetylgalactosaminyltransferase 2 ( $\beta 4$ GalNAcT-2) which synthetizes Sda epitope is decreased in CRC [83]. While T antigen is considered as an oncodevelopmental cancer-associated antigen and is overexpressed early during colon tumorigenesis, Tn and sTn antigens overexpression correlates with advanced and poorly differentiated colon carcinomas and is associated with a poor clinical outcome [84]. Moreover, mucin-type $\mathrm{C} 2 \mathrm{GnT}$ (C2GnT-M) expression, encoded by GCNT3 gene, is down-regulated in early stage colon cancer in comparison to normal colon tissues [85]. Its overexpression inhibits cell growth, adhesion, migration and invasion and induces apoptotic cell death [86]. Recently, González-Vallinas et al. revealed that 5-FU induces a significant dose-dependent overexpression 
of GCNT3 in sensitive parental SW620 colon cancer cell line but not in resistant one reinforcing the role of C2GnT-M in inhibition of tumor progression [85].

Drug resistance associated with dysregulation of expression, glycosylation and subcellular localization of mucins

Normal colon expresses highly MUC2, weakly MUC1, MUC3 and MUC4 and rarely MUC5AC, MUC5B and MUC6 [87-89]. Compared to normal tissues, hypoglycosylated MUC1 is overexpressed all over the surface of cancer cells and correlates with aggressiveness of carcinomas [90] whereas a decrease of MUC2 expression was described in colorectal adenocarcinoma but not in mucinous carcinomas [91, 92]. Recent studies demonstrate a relationship between the CRC classification and mucins expression pattern. According to genetic pathways involved, CRC follow the chromosomal instability (CIN) pathway with loss of heterozygosity $(\mathrm{LOH})$ of tumor suppressor genes (such as adenomatous polyposis coli (APC) and tumor protein 53 (TP53)) and activation of proto-oncogenes (such as V-Ki-ras2 Kirsten rat sarcoma viral oncogene homolog (KRAS)) or the microsatellite instability (MSI) pathway with frequent aberrations in the DNA mismatch repair (MMR) machinery [93]. A strong correlation was reported between a mucinous phenotype (overexpression of MUC2, MUC5AC and MUC6) and sporadic MSIhigh tumors characterized by V-Raf murine sarcoma viral oncogene homolog B (BRAF) mutation in which valine $(\mathrm{Val}, \mathrm{V})$ is substituted for glutamic acid (Glu, E) at residue 600 (p.V600E) and an extensive DNA methylation pattern also known as the $\mathrm{CpG}$ island methylator phenotype (CIMP) [94-96]. Increased secreted mucins expression can be attributed to promoters hypomethylation [95] and/ or activation of the EGFR-RAS-RAF pathway [97].

Lesuffleur et al. showed that, compared to parental sensitive HT-29 cells, the 5-FU resistant mucus-secreting subclone overexpressed MUC1, MUC2 and MUC4 and underexpressed MUC3 at the transcript level [98]. Interestingly, cells resistant to methotrexate exhibit a different profile of mucins expression [98]. The increased level of MUC2 transcript in 5-FU resistant HT-29 cells has been further confirmed by [99]. Patients suffering mucinous adenocarcinoma and receiving 5-FU show a diminished clinical response compared to those with nonmucinous tumors; this discrepancy likely results from a significant higher expression of TYMS gene encoding TS [100] (Figure 3). Mucinous tumors overexpress also glutathione S-transferase pi 1 (GSTP1) gene [100] encoding enzyme involved in the detoxification of platinum agents by glutathione (GSH) conjugation (Figure 3) expecting a weak response to oxaliplatin-treatment. CRC classified as MSI tumors showed higher mutation frequency and expression of TYMS than microsatellitestable (MSS) tumors [101, 102] suggesting a link between MSI status, mucinous profile and chemoresistance. The overexpression of $O$-glycosylated membrane-bound mucins can generate steric hindrance and mask surface antigens or decrease absorption of chemotherapy [103] (Figure 4A). In normal colon, there is no or a faint detection by monoclonal antibodies of the polypeptidic backbone of MUC1 which is masked by high density of long and complex mucin-type $O$-glycan chains. However, in CRC cells, MUC1 exhibits much shorter carbohydrate side-chains such as Tn and sTn allowing its immunodetection [104]. This aberrant glycosylation leads to MUC1 clathrin-mediated endocytosis [105]. It is also thought that MUC1 hypoglycosylation unmasks its polypeptidic core promoting MUC1 amino-terminal (N-ter) (MUC1-N) subunit proteolytic cleavage and release by extracellular proteases $[105,106]$. The internalization of MUC1 carboxy-terminal (C-ter) (MUC1-C) subunit may initiate oncogenic signaling $[105,106]$. Moreover, an increase in negatively charged sialic acid residues on MUC1 may contribute to metastasis progression by interfering with cell-cell adhesion. MUC1 confers resistance to reactive oxygen species (ROS)-induced apoptosis [107], hypoxia [108] and chemotherapeutic drugs [109]. Outer mitochondrial membrane localization of MUC1-C downregulates cisplatin-induced release of mitochondrial pro-apoptotic factors, activation of caspase- 3 and of the intrinsic apoptotic pathway in vitro and in vivo, in part, by stabilization of the mitochondrial membrane potential [109] (Figure 4C). MUC13 is also overexpressed in the cytoplasmic compartment of CRC carcinomas [110]. Its silencing sensitizes colon cancer cell lines to different DNA damaging agents including 5-FU, oxaliplatin, vincristine and doxorubicin in vitro, and suppresses tumor growth in vivo by decreasing subsequent activation of the nuclear factor-kappa B (NF- $\mathrm{kB}$ ) survival pathway [110]. However, the $O$-glycosylation profile of these mucins in CRC tumors has not been studied yet. Like for MUC1, an aberrant $O$-glycosylation of MUC13 may affect its subcellular localization and favor to activate oncogenic pathways. In this sense, it was speculated that overexpression of ppGalNAcT-14 contributes to ovarian carcinoma migration through truncated $O$-glycosylation of its substrates including MUC13 [111].

\section{ppGalNAcTs: key enzymes involved in multidrug resistance}

Treatment of CRC cells with benzyl-2-acetamido2-deoxy- $\alpha$-D-galactopyranoside (benzyl- $\alpha$-GalNAc), a structural analog of $\alpha$-GalNAc linked to serine or threonine residue which competitively inhibits core $1 O$-glycans extension, or benzyl- $\alpha$-GalNAc-derived oligosaccharides has been shown to induce apoptosis [112] and reduce sensitivity to TNF-related apoptosisinducing ligand (TRAIL) [113]. While knockdown of ppGalNAcT-3 decreases sensitivity of CRC cells to TRAIL (Table 1), expression of ppGalNAcT-14 correlates with responsiveness in pancreatic carcinoma, nonsmall-cell lung carcinoma (NSCLC) and melanoma. 
Notably, it was shown that ppGalNAcT-14 catalyzes the $O$-glycosylation of death receptors 4 and 5 (DR4 and DR5) in PSN-1 pancreatic cancer cells leading to TRAIL-induced receptors clustering and apoptosis. This $O$-glycosylation may stabilize death receptors in the plasma membrane or enhance their ligand-binding properties. In hepatocellular carcinoma, the single nucleotide polymorphism (SNP) marker rs9679162 "TT" genotype located in the ppGalNAcT-14 gene is associated with a favorable outcome in 5-FU, mitoxantrone and cisplatin combination chemotherapy treated patients [114]. It is suggested that ppGalNAcT-14 enhances sensitivity to therapy linked to TRAIL-mediated apoptosis through modulation of DR4 and/or DR5 $O$-glycosylation. However, biological effect of this genotype on the expression or activity of ppGalNAcT-14 is not yet known. In contrast, ppGalNAcT-14 "TT" genotype is correlated with poor outcome and tumor invasion in advanced CRC patients treated with oxaliplatin-based chemotherapy [115] (Table 1). The prognostic value of ppGalNAcT-14 "TT" genotype seems to be tissue and/or chemotherapydependent reflecting likely the involvement of different target glycoproteins.

\section{Altered fucosylation/sialylation profile of Lewis antigens associated with drug resistance in colorectal cancer}

Lewis carbohydrate determinants reside in glycolipids and glycoproteins at the surface of most epithelia (Figure 1) and are overexpressed in many carcinomas [12] including colon cancer [116]. Normal colon mucosa expresses complex glycans such as disialylLea and sialyl-6-sulfo-Lex at higher levels whereas the expression of sLea and sLex is quite low [117, 118]. The expression of these structures is inverted in CRC where increase of sLea and sLex amounts is associated with advanced tumors, metastasis occurrence and poor prognosis $[119,120]$. The interaction of these antigens with the adhesion molecule E-selectin in cytokineactivated endothelial cells has been proposed to play a role in the invasion and metastasis of cancer cells [121]. Leb and Ley are considered as typical oncofetal antigens in CRC (Figure 2) due to increased activity of $\alpha 2$ FucT

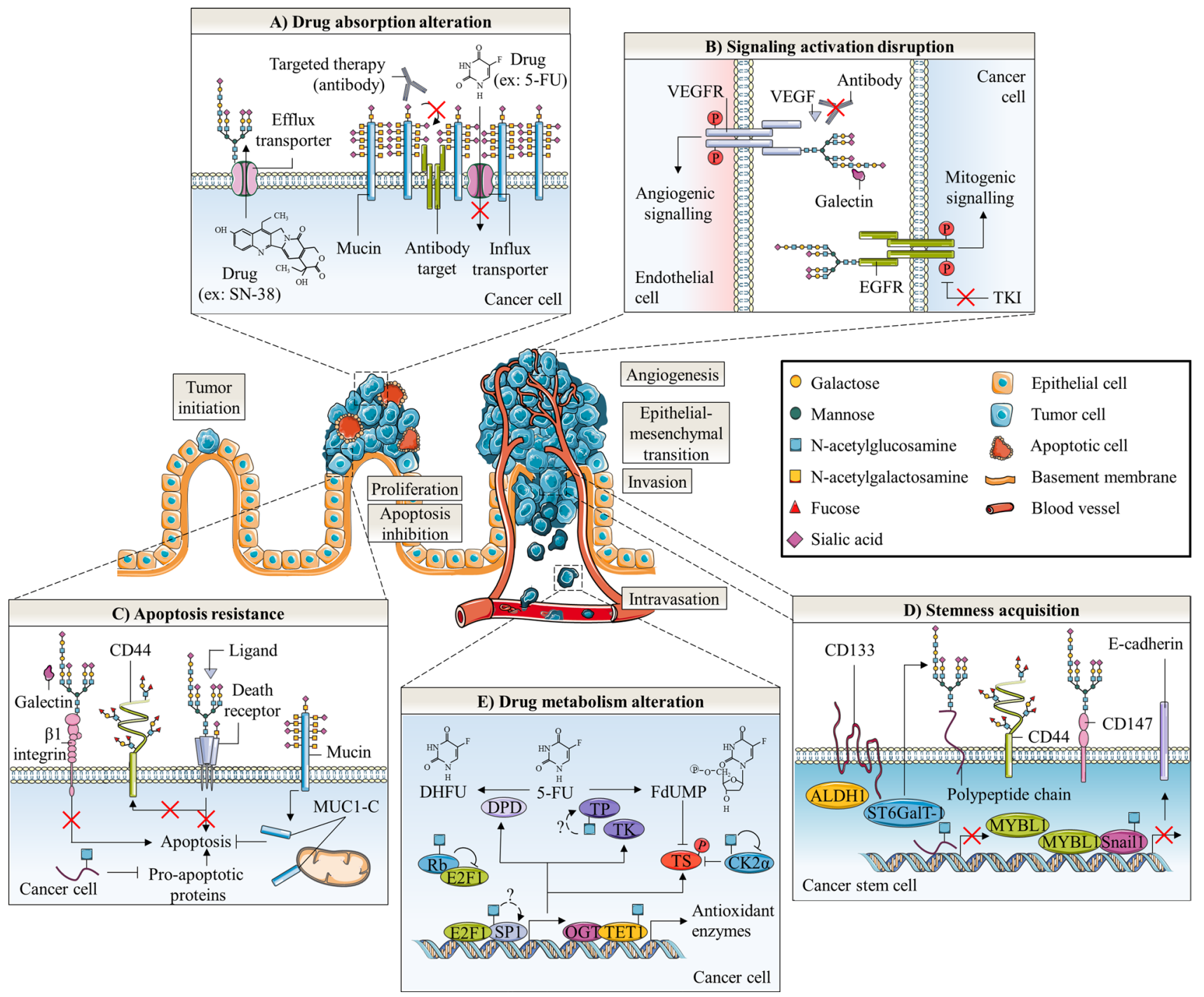


Figure 4: Glycosylation roles in anticancer therapy resistance of colorectal cancer. Abnormal glycosylation associated with colorectal cancer is involved in cancer emergence and progression as well as in different anticancer therapy resistance mechanisms. These later include altered drug absorption (A), signaling activation disruption (B), apoptosis resistance (C), cell stemness acquisition (D) and altered drug metabolism (E). A) Mucins could generate steric hindrance, mask surface antigen of targeted therapy and decrease absorption of chemotherapy. In contrast, $\mathrm{N}$-glycosylation can stabilize transporters responsible for efflux of chemotherapy drugs. B) On endothelial cells, aberrant $\beta 1,6$-GlcNAc bearing- $N$-glycans of VEGFR could promote its interaction with galectins and activate angiogenic signaling in the absence of ligand resulting in decreased efficacy of anti-VEGF treatment. In tumor cells, the presence of $\alpha 2,6$-sialylated terminal structure on EGFR could also decreased activity of the receptor and efficacy of TKI. C) Abnormal glycosylation of $\beta 1$ integrin prevents binding and pro-apoptotic activity of Gal. Both altered $N$ - and $O$-glycosylation of cell death receptors TNFR1, FasR, DR4 and DR5 inhibit induction of apoptosis. Fucosylation of Lewis antigen structures on CD44 could protect this CSC biomarker from proteolytic cleavage occurring in early steps of apoptosis. Truncated $O$-glycosylation of mucins promotes their intracellular accumulation and outer mitochondrial localization of MUC1-C could affect activation of the intrinsic apoptotic pathway. $O$-GlcNAcylation regulates expression of pro-apoptotic proteins. Altered $O$-GlcNAcylation could therefore induce resistance to apoptosis. D) The EMT process is supposed to generate CSC which have a slow proliferation rate and are thus less sensitive to chemotherapies. CRC CSC biomarkers CD44 and CD147 can be glycosylated. Expression of ST6GalT-1 is correlated with expression of ALDH1 and CD133 stem cell markers and proportion of CSC. The CRC CSC compartment could be regulated by the $O$-GlcNAcylation mediated-epigenetic down-regulation of MYBL1, a transcription activator of E-cadherin. $O$-GlcNAcylation also stabilizes the E-cadherin suppressor Snail1, essential for the loss of adherens junctions associated with EMT. E) $O$-GlcNAcylation may take fundamental part in regulation of 5-FU metabolism in colon cancer cells. OGT interacts with TET1 on promoter regions to activate transcription of antioxidant enzymes such as Nrf2. $O$-GlcNAcylation regulates both transcription factors Sp1 and E2F-1, which regulate a myriad of genes involved in nucleotide synthesis including enzymes involved in 5-FU catabolism and anabolism such as DHFR, TK and TS. E2F-1 is sequestered and inactived by binding to hypo-phosphorylated and $O$-GlcNAcylated Rb during early G1 phase of cell cycle. On the other hand, $O$-GlcNAcylation of E2F-1 was found to regulate its stability and its transcriptional activity but the specific biological effect in colon cancer cells has not been reported yet. TP was also found to be $O$-GlcNAcylated in breast tumors but the functional role of this glycosylation has not been studied. Finally, a Yin-Yang relation between phosphorylation and $O$-GlcNAcylation is expected to affect activity of TS, the target of active metabolite FdUMP. $O$-GlcNAcylation at Ser347 appears to decrease Thr344 phosphorylation and stability of CK2 $\alpha$. CK2 $\alpha$ is responsible for the phosphorylation at Ser124 and the decrease of catalytic activity of TS.

\section{$[35,36]$.}

Several studies describe a link between expression of fucosylated antigens and sensitivity of cancer cells to apoptosis. First, Goupille et al. showed that ectopic expression of rat $\alpha 2$ FucT FTA or FTB cDNA, respectively homologous to human FucT1 and FucT-2, increased levels of $\alpha 1,2$-fucosylated structures, tumorigenicity and resistance to apoptosis in spontaneously regressing REG rat colon adenocarcinoma cell clone [122]. Inversely, transfection of spontaneously tumorigenic PRO cells forming progressive tumors and presenting surface $\alpha 1,2$-fucosylated antigens with FTA antisense cDNA sensitized PRO cells to cell death (Table 1). An interplay between expression of $\mathrm{H} 2$ structures, the synthesis intermediates for Ley and Lex antigens (Figure 1 ), and cell response to 5-FU has also been observed [123]. In one hand, 5-FU treatment induces an increase of both $\alpha 2$ FucT activity and H2-type structures in vitro and in vivo. On the other hand, FTA knockdown and overexpression respectively increased and decreased cells sensitivity to 5-FU (Table 1). The involvement of $\alpha 1,2$-fucosylated antigens in the resistance to 5-FU treatment was further confirmed [124] (Table 1). One of the major identified glycoproteins carrying the H2type determinant is the CD44 adhesion molecule, a putative cancer stem cell marker [55, 123]. Normal colon cells express the standard form of CD44 (CD44s) whereas cancer cells may also express CD44 variants $(\mathrm{CD} 44 \mathrm{v})$ bearing supplementary domains underlying new oncogenic functions. In colon cancer, expression of CD44s is linked to EMT [125] and expression of
CD44v3 and v6 is associated with metastatic phenotype [126]. Depletion of the CD44s by proteolytic cleavage in early steps of Fas-triggered apoptosis contributes to loss of cell-cell and cell-matrix anchorage [127]. Moreover, resistant HT-29 and HCT-116 colon cancer cells to 5-FU, oxaliplatin and SN-38 showed a highest expression of CD44s compared to sensitive parental cells [128]. Cordel and collaborators speculated that increased expression of $\alpha 2 \mathrm{FucT}$ could participate in acquired-drug resistance by fucosylating CD44 and protecting it from proteolytic cleavage or strengthening cell adhesion [123] (Figure 4C). Yazawa et al. also found that 5-FU resistant DLD-1 colon carcinoma human cells have $\alpha 2 \mathrm{FucT}$ and $\alpha 3 F u c T$ higher activities and less of $\alpha 4 \mathrm{FucT}$ activity [124]. Treatment of these cells with the $\alpha 2$ FucT substrate phenyl $\beta$-galactoside decreased immunodetection of Ley, Leb and H2-type structures with YB-2 antifucosylated antibody and increased sensitivity to 5-FU suggesting the involvement of Leb and/or Ley antigens in the resistance mechanism. In parallel, expression of $\alpha 3 / 4$ FucT FucT-3 and $\alpha 3$ FucT FucT- 6 correlates with TRAIL sensitivity and it was shown that FucT-6 knockdown reduced DISC activation of pro-apoptotic caspase-8 in DLD-1 cells [113] (Table 1). Moreover, it was demonstrated that interferon gamma (IFN $\gamma$ ) and anti-Fas antibody treatment-mediated apoptosis induce an increase of transcript level of FucT-4, of $\alpha 2 \mathrm{FucT}$ and $\alpha 3 F u c T$ activities, and of Lex and Ley antigens at the cell surface [129]. Contradictory results showed that expression of Lex and Ley antigens was significantly diminished in colon cells treated by anti-Fas apoptosis 
inducers [130]. Finally, Yanagisawa et al. revealed that responder CRC patients to modified irinotecan/5-FU/ LV therapy harbor significant lower expression of sLex on core 2 branched mucin-type $O$-glycans [131] (Table $1)$. The nature of the fucosylated-antigens expressed at the cell surface of colorectal cancer cells might impact differently the mechanism of drug-induced apoptosis.

\section{$O$-GlcNAcylation and drug resistance in cancer: TERRA INCOGNITA}

$O$-GlcNAcylation is a recently discovered glycosylation whose role in cancer has been well studied in contrast to its involvement in drug response. In the following section, we will give a brief overview of what is known about $O$-GlcNAcylation in cancer before discussing the link with drug resistance.

\section{Upregulation of OGT and $O$-GlcNAcylation: impact in cancer}

An increased $O$-GlcNAcylation has been observed in many cancers [28, 132] including colon [133]. In colon cancer cells, the increased level of $O$-GlcNAcylation correlates with an overexpression of nucleocytoplasmic OGT [134, 135]. Contradictory findings are published concerning OGA expression. While Mi et al. did not report any change in OGA expression between colon cancer cells and normal adjacent tissues [133], Phueaouan et al. [136] and us $[134,135]$ observed instead an overexpression of OGA in vitro and in vivo. A fine cross-regulation between OGT and OGA expression was reported by different groups but the underlying mechanism by which each enzyme regulates the expression of the other is not fully understood. $O$-GlcNAcylation is an important regulator of cell proliferation, survival and migration especially through its interplay with phosphorylation [137]. $O$-GlcNAcylation targets and regulates the activity or the fate of oncoproteins such as $\beta$-catenin [134, 138-140], c-Myc [141, 142] and forkhead box protein M1 (FoxM1) [143], and of tumor suppressors like p53 [144] and the retinoblastoma protein $(\mathrm{Rb})$ [145]. O-GlcNAcylation is known to promote EMT in CRC. Beta-catenin is mutated in $10 \%$ of CRC [146] and its $O$-GlcNAcylation is suggested to participate in colorectal tumorigenesis in a context of glucose metabolism deregulation [147]. An elevation of $O$-GlcNAcylation in colon cancer cells reduced phosphorylation and ubiquitination of $\beta$-catenin increasing therefore its stability, reducing its localization to adherens junctions and enhancing its nuclear accumulation and activation [134, 138, 139]. Snail1 is a transcriptional repressor of epithelial cadherin (E-cadherin) whose expression is associated with EMT. Snaill is also stabilized by $O$-GlcNAcylation in colon cancer cells [148]. Reduced levels of $O$-GlcNAcylation diminished the colorectal CSC compartment in vivo by overexpression of the epigenetic regulation of MYB proto-oncogene like
1 (MYBL1), a transcriptional activator of E-cadherin [149] (Figure 4D). The key role of $O$-GlcNAcylation of other EMT actors has also been well highlighted [150, 151]. The comprehension of the mechanisms underlying the role of $O$-GlcNAcylation in cell apoptosis remains at its beginnings. However, some data give evidence that OGA and OGT isoforms play different roles in cell death signaling [152]. Thus, very few studies have examined specifically the role of $O$-GlcNAcylation in regulation of CRC cell death signaling. Elements of answer may be suggested according to studies in other cell types. First, an increase of global $O$-GlcNAcylation level was observed in Cos-7 green monkey kidney cells in response to cellular stresses strengthening the idea that $O$-GlcNAcylation enhances survival by regulating several cell death pathways $[153,154]$. Reducing $O$-GlcNAcylation in pancreatic ductal adenocarcinoma (PDAC) cell lines inhibits constitutive NF- $\mathrm{KB}$ activity and induces apoptosis [155] while, increased $O$-GlcNAcylation protects BxPC3 pancreatic adenocarcinoma cells against death [155]. Interestingly, OGT knockdown did not trigger apoptosis in non-transformed pancreatic duct epithelial (HPDE) cells. Similarly, OGT knockdown induces apoptosis in MDA-MB-231 breast cancer cells but not in MCF10A immortalized mammary epithelial cells through hypoxia-inducible factor 1- $\alpha$ (HIF-1 $\alpha$ ) degradation, decrease of glycolysis and ER stress pathway activation [156]. Yang et al. showed that p53 - the guardian of the genome - is stabilized by $O$-GlcNAcylation in MCF7 breast carcinoma cells [144]. Fardini et al. suggested a dual impact of $O$-GlcNAcylation on p53 depending upon the physiopathological context. The glycosylation promotes tumor suppressor activity of wild-type p53 and amplifies the pro-oncogenic activity of gain-of-function mutant form of p53 [28]. TP53 mutation status has been correlated to $\mathrm{CRC}$ response to drug therapy. In particular, the non-synonymous exonic SNP rs1042522 resulting in Pro substitution at codon 72 (P72) enhances the function of the protein. In fact, p53-P72 mutant has an increased capability to DNA binding and transcription activation of target genes. Interestingly, CRC patients carrying this gain-of-function mutation benefited most from 5-FU-based chemotherapies [157]. Recently, Gokare et al. demonstrated that p53-P72 repressed expression of dihydropyrimidine dehydrogenase (DPD), the rate-limiting enzyme in the 5-FU catabolism (Figure 3), following TS inhibition [158]. Thus, $O$-GlcNAcylation might play a role in 5-FU sensitivity by modulating activity of p53 wildtype and mutants.

The increasing number of evidences pointing out the crucial role of $O$-GlcNAcylation in the biological processes underlying tumorigenesis led to consider and then analyze this glycosylation and its related enzymes as potential actors of drug resistance. 


\section{$O$-GIcNAcylation and chemotherapy sensitivity}

Several studies have correlated expression of OGT and chemotherapy sensitivity. OGT silencing increases the sensitivity to 5 -FU of BCG-823 gastric cancer cell line by enhancing expression of p53 upregulated modulator of apoptosis (PUMA) and caspase-3 proapoptotic proteins [159]. In this sense, Pepe et al. showed in HepG2 hepatoblastoma cells that OGT stabilizes the transcriptional complex $\beta$-catenin/upstream stimulatory factor 1 (USF1) at the promoter of miR-483-3p, a microRNA responsible for transcription downregulation of PUMA [160]. Treatment with 2-deoxy-D-glucose (2-DG), a glucose-mimic inhibitor of glycolysis, reduces miR-483$3 p$ expression and increases sensitivity to 5 -FU-induced apoptosis. In 5-FU resistant SNUC5 colon cancer cells, OGT is overexpressed and interacts strongly with oxidative stress-activated ten-eleven translocation methylcytosine dioxygenase 1 (TET1) and histone H3 lysine 4 (H3K4) methyltransferase SET1/COMPASS (complex proteins associated with SET1) complex involved in the activation of gene expression [161]. $O$-GlcNAcylation is known to modulate recruitment, stability and activity of some chromatin regulators [162]. Particularly, OGT-mediated $O$-GlcNAcylation stabilizes TET1 [163] and OGT interacts preferentially with TET1 at gene promoters in close proximity of CpG-rich transcription start sites [164]. The multiprotein complex is recruited at the promoter region of nuclear factor erythroid 2-related factor $2(\mathrm{Nrf} 2)$, a major transcription factor driving antioxidant enzymes expression; the upregulation of the transcription factor would be responsible for 5-FU resistance [161] (Figure 4E; Table 1). A genome-wide mRNA expression profiling of the National Cancer Institute NCI-60 human tumor cell lines screen, comprising seven different colon cancer cell lines, revealed that OGT expression is negatively correlated with sensitivity to fluorodeoxyuridine monophosphate (FdUMP), the active metabolite of 5-FU responsible for TS inhibition (Figure 3; Table 1). However the authors did not found any correlation with fluorodeoxyuridine (FUdR), 5-FU, topotecan or irinotecan sensitivity [165]. In parallel, Temmink et al. analyzed genes expression of $\mathrm{H} 630$ colon cancer cell line resistant to trifluorothymidine (TFT), another thymidine analogue which shares the same 5-FU metabolic pathway to inhibit TS [166]. These resistant cells underexpressed thymidine kinase (TK) (Figure 3), human equilibrate nucleoside transporter (hENT also known as SLC29A) involved in anabolism of 5-FU and also OGT. A link between OGT expression and activation of anabolic pathways leading to formation of active FdUMP seems to occur. Inhibiting $O$-GlcNAcylation is a promising approach to improve the sensitivity of cancer cells to anti-cancer drugs. In the context of breast cancer, it has been shown that $O$-GlcNAcylation-increasing treatments reduce estrogen receptor $\alpha(\mathrm{ER} \alpha)$ expression and protect MCF-7 cells from death induced by tamoxifen, a chemical largely used as a partial antagonist of the estrogen receptor in ER positive breast cancers [167].

\section{$O$-GlcNAc regulation of resistance biomarkers}

No mechanistic studies have been carried out to understand precisely the role of OGT in chemotherapy cell response. However, several studies revealed that clinical biomarkers of drug resistance [41, 42] can be either directly or indirectly regulated by $O$-GlcNAcylation. Specificity protein 1 (Sp1) and E2F transcription factor-1 (E2F-1), two key transcription factors that regulate a myriad of genes involved in nucleotide synthesis such as those coding dihydrofolate reductase (DHFR), TK and TS are controlled by $O$-GlcNAcylation (Figures 3 and $4 \mathrm{E})$. E2F-1 is sequestered and inactivated by binding to hypo-phosphorylated and $O$-GlcNAcylated $\mathrm{Rb}$ during early G1 phase of cell cycle [145]. On the other hand, Sp1 was found to be $O$-GlcNAcylated in HT-29 colon cancer cells but the biological effect of the glycosylation was not reported [168] (Figure 4E). In breast cancer cells, $O$-GlcNAcylation of $\mathrm{Sp} 1$ regulates its stability and its transcriptional activity [169, 170]. In parallel, phosphorylation of TS at Ser124 by casein kinase $2 \alpha$ subunit $(\mathrm{CK} 2 \alpha)$ decreases its catalytic activity [171] but by interacting with $\mathrm{CK} 2 \alpha \mathrm{Thr} 344$ phosphorylation, $O$-GlcNAcylation at Ser347 decreases the stability of the kinase [172] (Figure 4E). Therefore, $O$-GlcNAcylation of CK2 $\alpha$ should indirectly increase catalytic activity of TS. Recently, $O$-GlcNAcylation of thymidine phosphorylase (TP), a key enzyme of 5-FU anabolism which catalyzes the formation of FUdR from 5-FU and deoxyribose-1phosphate (dRib-1-P) (Figure 3), was highlighted by mass spectrometry analysis of $O$-GlcNAcylated proteins enriched on succinyl-wheat germ agglutinin (sWGA) beads. TP was found to be $O$-GlcNAcylated only in breast tumors compared to adjacent healthy tissues but the role of this glycosylation has not been studied yet [173] (Figure $4 \mathrm{E}$ ). Finally, DNA topoisomerase 1 (Top1), the target of the irinotecan active metabolite SN-38 (Figure 3), is also modified by $O$-GlcNAcylation in vitro and in vivo; this PTM increases its supercoiled DNA helix relaxation activity [174]. Since it was reported a positive correlation between Top 1 activity and irinotecan sensitivity [175], $O$-GlcNAcylation may increase irinotecan sensibility through modification of Top1.

\section{CONCLUSIONS AND FUTURE PERSPECTIVES}

While the percentages of obese and diabetic individuals are progressing rapidly in industrialized countries, epidemiological data show these patients display an increased risk of colorectal cancer (CRC) [176] and relapse after chemotherapy treatment [177179]. These disorders may increase the availability of precursors involved in the biosynthesis of the nucleotide 
sugar donor uridine-5' -diphosphate-N-acetylglucosamine (UDP-GlcNAc) through the hexosamine biosynthetic pathway (HBP) and deregulate glycosylation processes. Oppositely, physical activity which has a blood glucose lowering effect appears to reduce risk of CRC recurrence following surgery combined with adjuvant chemotherapy [180]. However, glycosylation is a wide group of post-translational modifications and aberrant protein glycosylation is a common feature associated with cancer status and progression [27]. Thus, sialyl lewis a (sLea also referred to carbohydrate antigen CA 19-9) glycan and carcinoembryonic antigen (CEA) glycoprotein are serological tumor markers used actually to monitor CRC progression and disease recurrence [38].

The perspectives on emerging $N$-glycan-related anticancer therapies, along with new insights and challenges, are also currently being studied [181]. Recently, lectins have emerged as important biomedical tools that have been used in the development of anticancer agents. Several lectins have been shown to have the ability to discriminate between normal and tumor cells as a result of their different glycosylation patterns. Furthermore, the specific binding of lectins to cancer cells was shown to trigger mechanisms that promote the death of these abnormal cells. The review of de Oliveira Figueirôa and co-authors details the importance of lectins-carbohydrates interactions in cancer therapy and diagnosis [182]. They examine the use of nanoparticles exhibiting lectins (liposomes, solid lipid nanoparticles and other polymers) for anticancer drug delivery. They also discuss the development of drug delivery systems (alginate/chitosan microcapsules, alginate beads) carrying some antitumor lectins. In both cases (lectin-conjugated polymers or encapsulated lectins), these new pharmaceutical strategies improve intracellular delivery, bioavailability and cell targetability leading to enhanced therapeutic index and less side effects. In a very recent work, as sialoglycans overexpose the surface of cancer cells, sialic acid binding lectins have been explored for targeting cancer cells specifically. The potential of magnetic nanoparticles functionalized with wheat germ lectin (WGA) conjugates, so-called nanomagnetolectins, was thus successfully used as apoptotic targetable agents in vitro and in vivo for prostate cancer [183]. In addition to conventional drug therapy, lectin-based nanoparticles could specifically deliver to cancer cells gene or RNA interference (RNAi)based therapies targeting key enzymes involved in therapy response [184]. In parallel, therapeutic carbohydrate-based vaccines approaches [185] are developed to target cancerassociated glycans in CRC, such as CEA [186-188] or Thomsen-nouvelle antigens on mucin 1 (Tn-MUC1) [189]. Same innovative strategies are under development to break the immunotolerance linked to their embryonic origin and/or low expression level in normal tissues. Consequently, immune effectors can be recruited to kill cancer cells overexpressing these aberrant glycans. As highlighted in this review, because of evidences linking altered glycosylation and drug resistance in CRC, one could imagine to combine immunotherapy with standard drug therapy treatments to improve their efficiency. Targeting oncofetal glycans such as Leb, Ley or ThomsenFriedenreich antigen ( $\mathrm{T}$ antigen) could also be a promising approach because of their high cancer-specificity.

However, it was widely described that the success of chemotherapies collides with the appearance of highly drug-resistant cancer stem cells (CSC) carrying numerous molecular changes conferring them a capability to relapse as chemoresistant tumors [56]. A set of CSC biomarkers has been discovered but fail to be used in clinic because of their expression in adult stem cells. Therefore, identification and characterization of oncofetal stem cell markers, not expressed in adult tissue, becomes one of the more promising therapeutic strategy challenges for the highly specific CSC targeting. As previously reviewed [56], several studies that explored differential glycoproteins and glycolipids patterns between CSC and other cancer cells strongly suggest that the expression of short-chain $\mathrm{O}$-glycans is correlated with CSC phenotypes. Ferreira et al., therefore came up with a novel model that includes evaluation of glycomics and glycoproteomics in comprehensive pan-omics approaches envisaging more effective treatment strategy incorporating accurate patient classification and therapy design.

The literature findings summarized in this review provide evidence that abnormal glycosylation is also involved in diverse anticancer therapy resistance mechanisms including apoptosis failure, signaling activation disruption, altered drug absorption and metabolism, and cell stemness acquisition. However, our knowledge on this field remains limited. Understanding specific glycosylation alterations involved in resistance to CRC therapy can lead to the development of better therapeutic strategies with new predictive biomarkers and targets combined with an adapted diet.

\section{Abbreviations}

5-FU: 5-fluorouracil; $\alpha 2$ FucT: $\alpha 1,2$-fucosyltransferase; $\alpha 3 / 4$ FucT: $\alpha 1,3 / 4$-fucosyltransferase; $\beta 3 \mathrm{GnT}$ : $\beta 1,3-\mathrm{N}-$ acetylglucosaminyltransferase; ABC: ATP binding cassette; C2GnT: core $2 \beta 1,6-\mathrm{N}$-acetylglucosaminyltransferase; C3Gn $\mathrm{T}$ : core $3 \beta 1,3-\mathrm{N}$-acetylglucaminyltransferase; $\mathrm{C} 4 \mathrm{GnT}$ : core

$4 \mathrm{~N}$-acetylglucosaminyltransferase; CA: carbohydrate antigen; CEA: carcinoembryonic antigen; CMP-Neu5Ac: cytidine-5'-monophospho-N-acetylneuraminic acid; CRC: colorectal cancer; CSC: cancer stem cell; DISC: death inducting signaling complex; EGFR: epidermal growth factor receptor; EMT: epithelial-mesenchymal transition; ER: endoplasmic reticulum; Gal: galectin; GalNAc: N-acetylgalactosamine; GlcNAc: N-acetylglucosamine; GnT: N-acetylglucosaminyltransferase; HBP: hexosamine biosynthetic pathway; Le: Lewis; OGA: $O$-GlcNAcase; 
OGT: $O$-GlcNAc transferase; poly-LacNAc: poly$\mathrm{N}$-acetyllactosamine; ppGalNAcT: polypeptide N-acetylgalactosaminyltransferase; PTM: posttranslational modification; s: sialyl; SN-38: 7-ethyl-10hydroxycamptothecin; ST3GalT: $\alpha 2,3$-sialyltransferase; ST6GalNAcT: $\alpha$-GalNAc $\alpha 2,6$-sialyltransferase; ST6GalT: $\beta$-galactoside $\alpha 2,6$-sialyltransferase; $\mathrm{T}$ antigen: ThomsenFriedenreich antigen; $\mathrm{Tn}$ antigen: Thomsen-nouvelle antigen; TRAIL: TNF-related apoptosis-inducing ligand; TS: thymidylate synthetase; UDP-GalNAc: uridine-5'diphosphate-N-acetylgalactosamine; UDP-GlcNAc: uridine5'-diphosphate-N-acetylglucosamine; VEGF: vascular endothelial growth factor.

\section{ACKNOWLEDGMENTS AND FUNDING}

This work was supported by the "Ligue Contre le Cancer/Comité du Nord" the "Fondation ARC (Association pour la Recherche sur le Cancer)," the Région Nord-Pas de Calais (Cancer Regional Program), the University of Lille and the "Centre National de la Recherche Scientifique". The authors are also grateful to the "SIte de Recherche Intégré sur le Cancer" (SIRIC) ONCOLille and to FR 3688 FRABio. N.V. is the recipient of a fellowship from the "Ministère de l'Enseignement Supérieur et de la Recherche".

\section{CONFLICTS OF INTEREST}

None.

\section{REFERENCES}

1. Ferlay J, Soerjomataram I, Dikshit R, Eser S, Mathers C, Rebelo M, Parkin DM, Forman D, Bray F. Cancer incidence and mortality worldwide:Sources, methods and major patterns in GLOBOCAN 2012. Int J Cancer. 2015; 136:E359-86.

2. Tsikitis VL, Malireddy K, Green EA, Christensen B, Whelan R, Hyder J, Marcello P, Larach S, Lauter D, Sargent DJ, Nelson H. Postoperative surveillance recommendations for early stage colon cancer based on results from the clinical outcomes of surgical therapy trial. J Clin Oncol. 2009; 27:3671-6.

3. Yaffee P, Osipov A, Tan C, Tuli R, Hendifar A. Review of systemic therapies for locally advanced and metastatic rectal cancer. J Gastrointest Oncol. 2015; 6:185-200.

4. Ychou M, Rivoire M, Thezenas S, Quenet F, Delpero JR, Rebischung C, Letoublon C, Guimbaud R, Francois E, Ducreux M, Desseigne F, Fabre JM, Assenat E. A Randomized Phase II Trial of Three Intensified Chemotherapy Regimens in First-Line Treatment of Colorectal Cancer Patients with Initially Unresectable or Not Optimally Resectable Liver Metastases. The METHEP Trial. Ann Surg Oncol. 2013; 20:4289-97.
5. Siegel R, Ma J, Zou Z, Jemal A. Cancer statistics, 2014. CA Cancer J Clin. 2014; 64:9-29.

6. Moremen KW, Tiemeyer M, Nairn AV. Vertebrate protein glycosylation:diversity, synthesis and function. Nat Rev Mol Cell Biol. 2012; 13:448-62.

7. Apweiler R, Hermjakob H, Sharon N. On the frequency of protein glycosylation, as deduced from analysis of the SWISSPROT database. Biochim Biophys Acta. 1999; 1473:4-8.

8. Xu C, Ng DTW. Glycosylation-directed quality control of protein folding. Nat Rev Mol Cell Biol. 2015; 16:742-52.

9. Vasconcelos-dos-Santos A, Oliveira IA, Lucena MC, Mantuano NR, Whelan SA, Dias WB, Todeschini AR. Biosynthetic Machinery Involved in Aberrant Glycosylation:Promising Targets for Developing of Drugs Against Cancer. Front Oncol. 2015; 5.

10. Bennett EP, Mandel U, Clausen H, Gerken TA, Fritz TA, Tabak LA. Control of mucin-type O-glycosylation:A classification of the polypeptide GalNAc-transferase gene family. Glycobiology. 2012; 22:736-56.

11. Duarte HO, Freitas D, Gomes C, Gomes J, Magalhães A, Reis CA. Mucin-Type O-Glycosylation in Gastric Carcinogenesis. Biomolecules. 2016; 6.

12. Le Pendu J, Marionneau S, Cailleau-Thomas A, Rocher J, Le Moullac-Vaidye B, Clément M. ABH and Lewis histoblood group antigens in cancer. APMIS. 2001; 109:9-31.

13. Yang X, Qian K. Protein O-GlcNAcylation:emerging mechanisms and functions. Nat Rev Mol Cell Biol. 2017; 18:452-65.

14. Aquino-Gil M, Pierce A, Perez-Cervera Y, Zenteno E, Lefebvre T. OGT:a short overview of an enzyme standing out from usual glycosyltransferases. Biochem Soc Trans. 2017; 45:365-70.

15. Hardivillé S, Hart GW. Nutrient regulation of signaling, transcription, and cell physiology by O-GlcNAcylation. Cell Metab. 2014; 20:208-13.

16. Hart GW, Slawson C, Ramirez-Correa G, Lagerlof O. Cross talk between O-GlcNAcylation and phosphorylation:roles in signaling, transcription, and chronic disease. Annu Rev Biochem. 2011; 80:825-58.

17. Warburg O. On the origin of cancer cells. Science. 1956; 123:309-14.

18. Warburg O. On respiratory impairment in cancer cells. Science. 1956; 124:269-70.

19. DeBerardinis RJ, Lum JJ, Hatzivassiliou G, Thompson CB. The biology of cancer: metabolic reprogramming fuels cell growth and proliferation. Cell Metab. 2008; 7:11-20.

20. Schulze A, Harris AL. How cancer metabolism is tuned for proliferation and vulnerable to disruption. Nature. 2012; 491:364-73.

21. de Geus-Oei LF, Vriens D, van Laarhoven HWM, van der Graaf WTA, Oyen WJG. Monitoring and predicting response to therapy with $18 \mathrm{~F}-\mathrm{FDG}$ PET in colorectal cancer:a systematic review. J Nucl Med. 2009; 50 Suppl 1:43S-54S.

22. Marshall S, Bacote V, Traxinger RR. Discovery of a metabolic pathway mediating glucose-induced 
desensitization of the glucose transport system. Role of hexosamine biosynthesis in the induction of insulin resistance. J Biol Chem. 1991; 266:4706-12.

23. Kornfeld R. Studies on L-glutamine D-fructose 6-phosphate amidotransferase. I. Feedback inhibition by uridine diphosphateN-acetylglucosamine. J Biol Chem. 1967; 242:3135-41.

24. Clausen H, Bennett EP. A family of UDPGalNAc:polypeptide N-acetylgalactosaminyl-transferases control the initiation of mucin-type O-linked glycosylation. Glycobiology. 1996; 6:635-46.

25. Sasai K, Ikeda Y, Fujii T, Tsuda T, Taniguchi N. UDP-GlcNAc concentration is an important factor in the biosynthesis of beta1,6-branched oligosaccharides:regulation based on the kinetic properties of $\mathrm{N}$-acetylglucosaminyltransferase $\mathrm{V}$. Glycobiology. 2002; 12:119-27.

26. Torres CR, Hart GW. Topography and polypeptide distribution of terminal $\mathrm{N}$-acetylglucosamine residues on the surfaces of intact lymphocytes. Evidence for O-linked GlcNAc. J Biol Chem. 1984; 259:3308-17.

27. Pinho SS, Reis CA. Glycosylation in cancer:mechanisms and clinical implications. Nat Rev Cancer. 2015; 15:540-55.

28. Fardini $\mathrm{Y}$, Dehennaut $\mathrm{V}$, Lefebvre $\mathrm{T}$, Issad $\mathrm{T}$. O-GlcNAcylation:A New Cancer Hallmark? Front Endocrinol (Lausanne). 2013; 4:99.

29. Murata K, Miyoshi E, Kameyama M, Ishikawa O, Kabuto T, Sasaki Y, Hiratsuka M, Ohigashi H, Ishiguro S, Ito S, Honda H, Takemura F, Taniguchi N, et al. Expression of $\mathrm{N}$-acetylglucosaminyltransferase $\mathrm{V}$ in colorectal cancer correlates with metastasis and poor prognosis. Clin Cancer Res. 2000; 6:1772-7.

30. Ishida $H$, Togayachi A, Sakai $T$, Iwai $T$, Hiruma $\mathrm{T}$, Sato $\mathrm{T}$, Okubo $\mathrm{R}$, Inaba $\mathrm{N}$, Kudo $\mathrm{T}$, Gotoh $\mathrm{M}$, Shoda J, Tanaka N, Narimatsu H. A novel beta1,3-Nacetylglucosaminyltransferase (beta3Gn-T8), which synthesizes poly-N-acetyllactosamine, is dramatically upregulated in colon cancer. FEBS Lett. 2005; 579:71-8.

31. Hung JS, Huang J, Lin YC, Huang MJ, Lee PH, Lai HS, Liang JT, Huang MC. C1GALT1 overexpression promotes the invasive behavior of colon cancer cells through modifying O-glycosylation of FGFR2. Oncotarget. 2014; 5:2096-106. https://doi.org/10.18632/oncotarget.1815.

32. Iwai T, Kudo T, Kawamoto R, Kubota T, Togayachi A, Hiruma T, Okada T, Kawamoto T, Morozumi K, Narimatsu $\mathrm{H}$. Core 3 synthase is down-regulated in colon carcinoma and profoundly suppresses the metastatic potential of carcinoma cells. Proc Natl Acad Sci USA. 2005; 102:4572-7.

33. Vavasseur F, Dole K, Yang J, Matta KL, Myerscough N, Corfield A, Paraskeva C, Brockhausen I. O-glycan biosynthesis in human colorectal adenoma cells during progression to cancer. Eur J Biochem. 1994; 222:415-24.

34. Abe K, Hakomori S, Ohshiba S. Differential expression of difucosyl type 2 chain (LeY) defined by monoclonal antibody AH6 in different locations of colonic epithelia, various histological types of colonic polyps, and adenocarcinomas. Cancer Res. 1986; 46:2639-44.
35. Muinelo-Romay L, Gil-Martín E, Fernández-Briera A. $\alpha(1,2)$ fucosylation in human colorectal carcinoma. Oncol Lett. 2010; 1:361-6.

36. Yazawa S, Nakamura J, Asao T, Nagamachi Y, Sagi M, Matta KL, Tachikawa T, Akamatsu M. Aberrant alpha 1-->2fucosyltransferases found in human colorectal carcinoma involved in the accumulation of Leb and Y antigens in colorectal tumors. Jpn J Cancer Res. 1993; 84:989-95.

37. Yuan M, Itzkowitz SH, Palekar A, Shamsuddin AM, Phelps PC, Trump BF, Kim YS. Distribution of blood group antigens A, B, H, Lewisa, and Lewisb in human normal, fetal, and malignant colonic tissue. Cancer Res. 1985; 45:4499-511.

38. Bagaria B, Sood S, Sharma R, Lalwani S. Comparative study of CEA and CA19-9 in esophageal, gastric and colon cancers individually and in combination (ROC curve analysis). Cancer Biol Med. 2013; 10:148-57.

39. Venkitachalam S, Revoredo L, Varadan V, Fecteau RE, Ravi L, Lutterbaugh J, Markowitz SD, Willis JE, Gerken TA, Guda K. Biochemical and functional characterization of glycosylation-associated mutational landscapes in colon cancer. Scientific Reports. 2016; 6:srep23642.

40. Hamaguchi J, Nakagawa $H$, Takahashi M, Kudo T, Kamiyama N, Sun B, Oshima T, Sato Y, Deguchi K, Todo S, Nishimura SI. Swainsonine reduces 5-fluorouracil tolerance in the multistage resistance of colorectal cancer cell lines. Mol Cancer. 2007; 6:58.

41. Hammond WA, Swaika A, Mody K. Pharmacologic resistance in colorectal cancer:a review. Ther Adv Med Oncol. 2016; 8:57-84.

42. Mohelnikova-Duchonova B, Melichar B, Soucek P. FOLFOX/FOLFIRI pharmacogenetics:the call for a personalized approach in colorectal cancer therapy. World J Gastroenterol. 2014; 20:10316-30.

43. Nakagawa H, Wakabayashi-Nakao K, Tamura A, Toyoda Y, Koshiba S, Ishikawa T. Disruption of N-linked glycosylation enhances ubiquitin-mediated proteasomal degradation of the human ATP-binding cassette transporter ABCG2. FEBS J. 2009; 276:7237-52.

44. Santos FM, Latorre AO, Hueza IM, Sanches DS, Lippi LL, Gardner DR, Spinosa HS. Increased antitumor efficacy by the combined administration of swainsonine and cisplatin in vivo. Phytomedicine. 2011; 18:1096-101.

45. Fernandes B, Sagman U, Auger M, Demetrio M, Dennis JW. Beta 1-6 branched oligosaccharides as a marker of tumor progression in human breast and colon neoplasia. Cancer Res. 1991; 51:718-23.

46. Yamamoto H, Swoger J, Greene S, Saito T, Hurh J, Sweeley C, Leestma J, Mkrdichian E, Cerullo L, Nishikawa A, Ihara Y, Taniguchi N, Moskal JR. Beta1,6-N-acetylglucosaminebearing $\mathrm{N}$-glycans in human gliomas:implications for a role in regulating invasivity. Cancer Res. 2000; 60:134-42.

47. Kim YS, Hwang SY, Kang HY, Sohn H, Oh S, Kim JY, Yoo JS, Kim YH, Kim CH, Jeon JH, Lee JM, Kang HA, Miyoshi E, et al. Functional proteomics study reveals that 
$\mathrm{N}$-Acetylglucosaminyltransferase $\mathrm{V}$ reinforces the invasive/ metastatic potential of colon cancer through aberrant glycosylation on tissue inhibitor of metalloproteinase-1. Mol Cell Proteomics. 2008; 7:1-14.

48. Croci DO, Cerliani JP, Dalotto-Moreno T, MéndezHuergo SP, Mascanfroni ID, Dergan-Dylon S, Toscano MA, Caramelo JJ, García-Vallejo JJ, Ouyang J, Mesri EA, Junttila MR, Bais C, et al. Glycosylation-dependent lectinreceptor interactions preserve angiogenesis in anti-VEGF refractory tumors. Cell. 2014; 156:744-58.

49. Cagnoni AJ, Pérez Sáez JM, Rabinovich GA, Mariño KV. Turning-Off Signaling by Siglecs, Selectins, and Galectins:Chemical Inhibition of Glycan-Dependent Interactions in Cancer. Front Oncol. 2016; 6.

50. García-Alfonso P, Grande E, Polo E, Afonso R, Reina JJ, Jorge M, Campos JM, Martínez V, Ángeles C, Montagut $\mathrm{C}$. The role of antiangiogenic agents in the treatment of patients with advanced colorectal cancer according to K-RAS status. Angiogenesis. 2014; 17:805-21.

51. Ni J, Jiang Z, Shen L, Gao L, Yu M, Xu X, Zou S, Hua D, Wu S. $33 \mathrm{GnT} 8$ regulates the metastatic potential of colorectal carcinoma cells by altering the glycosylation of CD147. Oncol Rep. 2014; 31:1795-801.

52. Sun J, Hemler ME. Regulation of MMP-1 and MMP2 production through CD147/extracellular matrix metalloproteinase inducer interactions. Cancer Res. 2001; 61:2276-81.

53. Shen $\mathrm{L}, \mathrm{Yu} \mathrm{M}, \mathrm{Xu} \mathrm{X}$, Gao L, Ni J, Luo Z, Wu S. Knockdown of $\beta 3 \mathrm{GnT} 8$ reverses 5 -fluorouracil resistance in human colorectal cancer cells via inhibition the biosynthesis of polylactosamine-type N-glycans. Int J Oncol. 2014; 45:2560-8.

54. Chen J, Pan Y, He B, Ying H, Wang F, Sun H, Deng Q, Liu X, Lin K, Peng H, Cho WC, Wang S. Inhibition of CD147 expression by RNA interference reduces proliferation, invasion and increases chemosensitivity in cancer stem celllike HT-29 cells. Int J Oncol. 2015; 47:1476-84.

55. Dalerba P, Dylla SJ, Park IK, Liu R, Wang X, Cho RW, Hoey T, Gurney A, Huang EH, Simeone DM, Shelton AA, Parmiani G, Castelli C, et al. Phenotypic characterization of human colorectal cancer stem cells. Proc Natl Acad Sci USA. 2007; 104:10158-63.

56. Ferreira JA, Peixoto A, Neves M, Gaiteiro C, Reis CA, Assaraf YG, Santos LL. Mechanisms of cisplatin resistance and targeting of cancer stem cells:Adding glycosylation to the equation. Drug Resistance Updates. 2016; 24:34-54.

57. Lin Q, Yun Z. Impact of the Hypoxic Tumor Microenvironment on the Regulation of Cancer Stem Cell Characteristics. Cancer Biol Ther. 2010; 9:949-56.

58. Xu T, Zhou M, Peng L, Kong S, Miao R, Shi Y, Sheng $\mathrm{H}, \mathrm{Li}$ L. Upregulation of CD147 promotes cell invasion, epithelial-to-mesenchymal transition and activates MAPK/ ERK signaling pathway in colorectal cancer. Int J Clin Exp Pathol. 2014; 7:7432-41.
59. Brabletz T, Hlubek F, Spaderna S, Schmalhofer O, Hiendlmeyer E, Jung A, Kirchner T. Invasion and metastasis in colorectal cancer:epithelial-mesenchymal transition, mesenchymal-epithelial transition, stem cells and betacatenin. Cells Tissues Organs. 2005; 179:56-65.

60. Creighton CJ, Li X, Landis M, Dixon JM, Neumeister VM, Sjolund A, Rimm DL, Wong H, Rodriguez A, Herschkowitz JI, Fan C, Zhang X, He X, et al. Residual breast cancers after conventional therapy display mesenchymal as well as tumor-initiating features. Proc Natl Acad Sci USA. 2009; 106:13820-5.

61. Peng L, Zhu H, Wang J, Sui H, Zhang H, Jin C, Li L, Xu T, Miao R. MiR-492 is functionally involved in Oxaliplatin resistance in colon cancer cells LS174T via its regulating the expression of CD147. Mol Cell Biochem. 2015; 405:73-9.

62. Garza-Treviño EN, Said-Fernández SL, MartínezRodríguez HG. Understanding the colon cancer stem cells and perspectives on treatment. Cancer Cell Int. 2015; 15.

63. Fanali C, Lucchetti D, Farina M, Corbi M, Cufino V, Cittadini A, Sgambato A. Cancer stem cells in colorectal cancer from pathogenesis to therapy:Controversies and perspectives. World J Gastroenterol. 2014; 20:923-42.

64. Dall'Olio F, Malagolini N, di Stefano G, Minni F, Marrano D, Serafini-Cessi F. Increased CMP-NeuAc:Gal beta 1,4GlcNAc-R alpha 2,6 sialyltransferase activity in human colorectal cancer tissues. Int J Cancer. 1989; 44:434-9.

65. $\mathrm{Lu} \mathrm{J,} \mathrm{Gu}$ J. Significance of $\beta$-Galactoside $\alpha 2,6$ Sialyltranferase 1 in Cancers. Molecules. 2015; 20:7509-27.

66. Seales EC, Jurado GA, Singhal A, Bellis SL. Ras oncogene directs expression of a differentially sialylated, functionally altered beta1 integrin. Oncogene. 2003; 22:7137-45.

67. Park JJ, Yi JY, Jin YB, Lee YJ, Lee JS, Lee YS, Ko YG, Lee M. Sialylation of epidermal growth factor receptor regulates receptor activity and chemosensitivity to gefitinib in colon cancer cells. Biochem Pharmacol. 2012; 83:849-57.

68. Seales EC, Jurado GA, Brunson BA, Wakefield JK, Frost AR, Bellis SL. Hypersialylation of beta1 integrins, observed in colon adenocarcinoma, may contribute to cancer progression by up-regulating cell motility. Cancer Res. 2005; 65:4645-52.

69. Swindall AF, Londoño-Joshi AI, Schultz MJ, Fineberg N, Buchsbaum DJ, Bellis SL. ST6Gal-I protein expression is upregulated in human epithelial tumors and correlates with stem cell markers in normal tissues and colon cancer cell lines. Cancer Res. 2013; 73:2368-78.

70. Lise M, Belluco C, Perera SP, Patel R, Thomas P, Ganguly A. Clinical correlations of alpha2,6-sialyltransferase expression in colorectal cancer patients. Hybridoma. 2000; 19:281-6.

71. Isaji T, Im S, Gu W, Wang Y, Hang Q, Lu J, Fukuda T, Hashii N, Takakura D, Kawasaki N, Miyoshi H, Gu J. An oncogenic protein Golgi phosphoprotein 3 up-regulates cell migration via sialylation. J Biol Chem. 2014; 289:20694-705. 
72. Zhao Y, Li Y, Ma H, Dong W, Zhou H, Song X, Zhang J, Jia L. Modification of sialylation mediates the invasive properties and chemosensitivity of human hepatocellular carcinoma. Mol Cell Proteomics. 2014; 13:520-36.

73. Zhuo Y, Chammas R, Bellis SL. Sialylation of beta1 integrins blocks cell adhesion to galectin-3 and protects cells against galectin-3-induced apoptosis. J Biol Chem. 2008; 283:22177-85.

74. Liu YC, Yen HY, Chen CY, Chen CH, Cheng PF, Juan YH, Chen CH, Khoo KH, Yu CJ, Yang PC, Hsu TL, Wong CH. Sialylation and fucosylation of epidermal growth factor receptor suppress its dimerization and activation in lung cancer cells. Proc Natl Acad Sci U S A. 2011; 108:11332-7.

75. Moroni M, Veronese S, Benvenuti S, Marrapese G, SartoreBianchi A, Di Nicolantonio F, Gambacorta M, Siena S, Bardelli A. Gene copy number for epidermal growth factor receptor (EGFR) and clinical response to antiEGFR treatment in colorectal cancer:a cohort study. Lancet Oncol. 2005; 6:279-86.

76. Sartore-Bianchi A, Moroni M, Veronese S, Carnaghi C, Bajetta E, Luppi G, Sobrero A, Barone C, Cascinu S, Colucci G, Cortesi E, Nichelatti M, Gambacorta M, et al. Epidermal growth factor receptor gene copy number and clinical outcome of metastatic colorectal cancer treated with panitumumab. J Clin Oncol. 2007; 25:3238-45.

77. Swindall AF, Bellis SL. Sialylation of the Fas death receptor by ST6Gal-I provides protection against Fas-mediated apoptosis in colon carcinoma cells. J Biol Chem. 2011; 286:22982-90.

78. Liu Z, Swindall AF, Kesterson RA, Schoeb TR, Bullard DC, Bellis SL. ST6Gal-I regulates macrophage apoptosis via $\alpha 2-6$ sialylation of the TNFR1 death receptor. J Biol Chem. 2011; 286:39654-62.

79. $\mathrm{Hu} \mathrm{T}$, Li Z, Gao CY, Cho CH. Mechanisms of drug resistance in colon cancer and its therapeutic strategies. World J Gastroenterol. 2016; 22:6876-89.

80. Zhang L, Yu J. Role of apoptosis in colon cancer biology, therapy, and prevention. Curr Colorectal Cancer Rep. 2013; 9.

81. Bates DJP, Lewis LD. Manipulating the apoptotic pathway:potential therapeutics for cancer patients. Br J Clin Pharmacol. 2013; 76:381-95.

82. Capon C, Maes E, Michalski JC, Leffler H, Kim YS. Sd(a)antigen-like structures carried on core 3 are prominent features of glycans from the mucin of normal human descending colon. Biochem J. 2001; 358:657-64.

83. Malagolini N, Santini D, Chiricolo M, Dall'Olio F. Biosynthesis and expression of the Sda and sialyl Lewis $\mathrm{x}$ antigens in normal and cancer colon. Glycobiology. 2007; 17:688-97.

84. Itzkowitz SH, Yuan M, Montgomery CK, Kjeldsen T, Takahashi HK, Bigbee WL, Kim YS. Expression of Tn, sialosyl-Tn, and T antigens in human colon cancer. Cancer Res. 1989; 49:197-204.

85. González-Vallinas M, Vargas T, Moreno-Rubio J, Molina S, Herranz J, Cejas P, Burgos E, Aguayo C, Custodio A, Reglero G, Feliu J, Ramírez de Molina A. Clinical relevance of the differential expression of the glycosyltransferase gene GCNT3 in colon cancer. Eur J Cancer. 2015; 51:1-8.

86. Huang MC, Chen HY, Huang HC, Huang J, Liang JT, Shen TL, Lin NY, Ho CC, Cho IM, Hsu SM. C2GnTM is downregulated in colorectal cancer and its re-expression causes growth inhibition of colon cancer cells. Oncogene. 2006; 25:3267-76.

87. Audie JP, Janin A, Porchet N, Copin MC, Gosselin B, Aubert JP. Expression of human mucin genes in respiratory, digestive, and reproductive tracts ascertained by in situ hybridization. J Histochem Cytochem. 1993; 41:1479-85.

88. Ho SB, Niehans GA, Lyftogt C, Yan PS, Cherwitz DL, Gum ET, Dahiya R, Kim YS. Heterogeneity of mucin gene expression in normal and neoplastic tissues. Cancer Res. 1993; 53:641-51.

89. Lesuffleur T, Zweibaum A, Real FX. Mucins in normal and neoplastic human gastrointestinal tissues. Crit Rev Oncol Hematol. 1994; 17:153-80.

90. Nakamori S, Ota DM, Cleary KR, Shirotani K, Irimura T. MUC1 mucin expression as a marker of progression and metastasis of human colorectal carcinoma. Gastroenterology. 1994; 106:353-61.

91. Blank M, Klussmann E, Krüger-Krasagakes S, SchmittGräff A, Stolte M, Bornhoeft G, Stein H, Xing PX, McKenzie IF, Verstijnen CP. Expression of MUC2-mucin in colorectal adenomas and carcinomas of different histological types. Int J Cancer. 1994; 59:301-6.

92. Byrd JC, Bresalier RS. Mucins and mucin binding proteins in colorectal cancer. Cancer Metastasis Rev. 2004; 23:77-99.

93. Armaghany T, Wilson JD, Chu Q, Mills G. Genetic Alterations in Colorectal Cancer. Gastrointest Cancer Res. 2012; 5:19-27.

94. Walsh MD, Clendenning M, Williamson E, Pearson SA, Walters RJ, Nagler B, Packenas D, Win AK, Hopper JL, Jenkins MA, Haydon AM, Rosty C, English DR, et al. Expression of MUC2, MUC5AC, MUC5B, and MUC6 mucins in colorectal cancers and their association with the $\mathrm{CpG}$ island methylator phenotype. Mod Pathol. 2013; 26:1642-56.

95. Renaud F, Vincent A, Mariette C, Crépin M, Stechly L, Truant S, Copin MC, Porchet N, Leteurtre E, Van Seuningen I, Buisine MP. MUC5AC hypomethylation is a predictor of microsatellite instability independently of clinical factors associated with colorectal cancer. Int J Cancer. 2015; 136:2811-21.

96. Renaud F, Mariette C, Vincent A, Wacrenier A, Maunoury V, Leclerc J, Coppin L, Crépin M, Van Seuningen I, Leteurtre E, Buisine MP. The serrated neoplasia pathway of colorectal tumors:Identification of MUC5AC hypomethylation as an early marker of polyps with malignant potential. Int $\mathrm{J}$ Cancer. 2016; 138:1472-81.

97. Perrais M, Pigny P, Copin MC, Aubert JP, Van Seuningen I. Induction of MUC2 and MUC5AC mucins by factors of the epidermal growth factor (EGF) family is mediated by EGF receptor/Ras/Raf/extracellular signal-regulated kinase cascade and Sp1. J Biol Chem. 2002; 277:32258-67. 
98. Lesuffleur T, Porchet N, Aubert JP, Swallow D, Gum JR, Kim YS, Real FX, Zweibaum A. Differential expression of the human mucin genes MUC1 to MUC5 in relation to growth and differentiation of different mucus-secreting HT29 cell subpopulations. J Cell Sci. 1993; 106:771-83.

99. Choi SR, Cho M, Kim HR, Ahn DH, Sleisenger MH, Kim YS. Biological properties and expression of mucins in 5-fluorouracil resistant HT29 human colon cancer cells. Int J Oncol. 2000; 17:141-7.

100. Glasgow SC, Yu J, Carvalho LP, Shannon WD, Fleshman JW, McLeod HL. Unfavourable expression of pharmacologic markers in mucinous colorectal cancer. $\mathrm{Br}$ J Cancer. 2005; 92:259-64.

101. Tian S, Roepman P, Popovici V, Michaut M, Majewski I, Salazar R, Santos C, Rosenberg R, Nitsche U, Mesker WE, Bruin S, Tejpar S, Delorenzi M, et al. A robust genomic signature for the detection of colorectal cancer patients with microsatellite instability phenotype and high mutation frequency. J Pathol. 2012; 228:586-95.

102. Vilar E, Mukherjee B, Kuick R, Raskin L, Misek DE, Taylor JMG, Giordano TJ, Hanash SM, Fearon ER, Rennert $\mathrm{G}$, Gruber SB. Gene expression patterns in mismatch repair-deficient colorectal cancers highlight the potential therapeutic role of inhibitors of the phosphatidylinositol 3-kinase-AKT-mammalian target of rapamycin pathway. Clin Cancer Res. 2009; 15:2829-39.

103. Kalra AV, Campbell RB. Mucin overexpression limits the effectiveness of 5-FU by reducing intracellular drug uptake and antineoplastic drug effects in pancreatic tumours. Eur J Cancer. 2009; 45:164-73.

104. Krishn SR, Kaur S, Smith LM, Johansson SL, Jain M, Patel A, Gautam SK, Hollingsworth MA, Mandel U, Clausen H, Lo WC, Fan WTL, Manne U, et al. Mucins and associated glycan signatures in colon adenoma-carcinoma sequence:Prospective pathological implication(s) for early diagnosis of colon cancer. Cancer Lett. 2016; 374:304-14.

105. Altschuler Y, Kinlough CL, Poland PA, Bruns JB, Apodaca G, Weisz OA, Hughey RP. Clathrin-mediated endocytosis of MUC1 is modulated by its glycosylation state. Mol Biol Cell. 2000; 11:819-31.

106. Nath S, Mukherjee P. MUC1:a multifaceted oncoprotein with a key role in cancer progression. Trends Mol Med. 2014; 20:332-42.

107. Yin L, Huang L, Kufe D. MUC1 oncoprotein activates the FOXO3a transcription factor in a survival response to oxidative stress. J Biol Chem. 2004; 279:45721-7.

108. Yin L, Kharbanda S, Kufe D. Mucin 1 oncoprotein blocks hypoxia-inducible factor 1alpha activation in a survival response to hypoxia. J Biol Chem. 2007; 282:257-66.

109. Ren J, Agata N, Chen D, Li Y, Yu W, Huang L, Raina D, Chen W, Kharbanda S, Kufe D. Human MUC1 carcinomaassociated protein confers resistance to genotoxic anticancer agents. Cancer Cell. 2004; 5:163-75.

110. Sheng YH, He Y, Hasnain SZ, Wang R, Tong H, Clarke DT, Lourie R, Oancea I, Wong KY, Lumley JW, Florin TH,
Sutton P, Hooper JD, et al. MUC13 protects colorectal cancer cells from death by activating the NF- $\kappa \mathrm{B}$ pathway and is a potential therapeutic target. Oncogene. 2017; 36:700-13.

111. Wang R, Yu C, Zhao D, Wu M, Yang Z. The mucin-type glycosylating enzyme polypeptide $\mathrm{N}$-acetylgalactosaminyltransferase 14 promotes the migration of ovarian cancer by modifying mucin 13 . Oncol Rep. 2013; 30:667-76.

112. Patsos G, Hebbe-Viton V, Robbe-Masselot C, Masselot D, Martin RS, Greenwood R, Paraskeva C, Klein A, Graessmann M, Michalski JC, Gallagher T, Corfield A. O-Glycan inhibitors generate aryl-glycans, induce apoptosis and lead to growth inhibition in colorectal cancer cell lines. Glycobiology. 2009; 19:382-98.

113. Wagner KW, Punnoose EA, Januario T, Lawrence DA, Pitti RM, Lancaster K, Lee D, von Goetz M, Yee SF, Totpal K, Huw L, Katta V, Cavet G, et al. Death-receptor O-glycosylation controls tumor-cell sensitivity to the proapoptotic ligand Apo2L/TRAIL. Nat Med. 2007; 13:1070-7.

114. Yeh CT, Liang KH, Lin CC, Chang ML, Hsu CL, Hung CF. A single nucleotide polymorphism on the GALNT14 gene as an effective predictor of response to chemotherapy in advanced hepatocellular carcinoma. Int J Cancer. 2014; 134:1214-24.

115. Lin WR, Chiang JM, Liang KH, Lim SN, Lai MW, Tsou YK, Hsieh TY, Hsu CK, Yeh CT. GALNT14 Genotype Predicts Postoperative Outcome of Stage III Colorectal Cancer With Oxaliplatin as Adjuvant Chemotherapy. Medicine (Baltimore). 2016; 95:e3487.

116. Sakamoto J, Furukawa K, Cordon-Cardo C, Yin BW, Rettig WJ, Oettgen HF, Old LJ, Lloyd KO. Expression of Lewisa, Lewisb, $\mathrm{X}$, and $\mathrm{Y}$ blood group antigens in human colonic tumors and normal tissue and in human tumor-derived cell lines. Cancer Res. 1986; 46:1553-61.

117. Izawa M, Kumamoto K, Mitsuoka C, Kanamori C, Kanamori A, Ohmori K, Ishida H, Nakamura S, KurataMiura K, Sasaki K, Nishi T, Kannagi R. Expression of sialyl 6-sulfo Lewis $\mathrm{X}$ is inversely correlated with conventional sialyl Lewis $\mathrm{X}$ expression in human colorectal cancer. Cancer Res. 2000; 60:1410-6.

118. Miyazaki K, Ohmori K, Izawa M, Koike T, Kumamoto K, Furukawa K, Ando T, Kiso M, Yamaji T, Hashimoto Y, Suzuki A, Yoshida A, Takeuchi M, et al. Loss of disialyl Lewis(a), the ligand for lymphocyte inhibitory receptor sialic acid-binding immunoglobulin-like lectin-7 (Siglec-7) associated with increased sialyl Lewis(a) expression on human colon cancers. Cancer Res. 2004; 64:4498-505.

119. Konno A, Hoshino Y, Terashima S, Motoki R, Kawaguchi T. Carbohydrate expression profile of colorectal cancer cells is relevant to metastatic pattern and prognosis. Clin Exp Metastasis. 2002; 19:61-70.

120. Nakayama T, Watanabe M, Katsumata T, Teramoto T, Kitajima M. Expression of sialyl Lewis(a) as a new prognostic factor for patients with advanced colorectal carcinoma. Cancer. 1995; 75:2051-6. 
121. Takada A, Ohmori K, Yoneda T, Tsuyuoka K, Hasegawa A, Kiso M, Kannagi R. Contribution of carbohydrate antigens sialyl Lewis A and sialyl Lewis X to adhesion of human cancer cells to vascular endothelium. Cancer Res. 1993; 53:354-61.

122. Goupille C, Marionneau S, Bureau V, Hallouin F, Meichenin M, Rocher J, Le Pendu J. alpha1,2Fucosyltransferase increases resistance to apoptosis of rat colon carcinoma cells. Glycobiology. 2000; 10:375-82.

123. Cordel S, Goupille C, Hallouin F, Meflah K, Le Pendu J. Role for alpha1,2-fucosyltransferase and histo-blood group antigen $\mathrm{H}$ type 2 in resistance of rat colon carcinoma cells to 5-fluorouracil. Int J Cancer. 2000; 85:142-8.

124. Yazawa S, Nishimura T, Ide M, Asao T, Okamura A, Tanaka S, Takai I, Yagihashi Y, Saniabadi AR, Kochibe N. Tumor-related expression of alpha1,2fucosylated antigens on colorectal carcinoma cells and its suppression by cell-mediated priming using sugar acceptors for alpha1,2fucosyltransferase. Glycobiology. 2002; 12:545-53.

125. Mashita N, Yamada S, Nakayama G, Tanaka C, Iwata N, Kanda M, Kobayashi D, Fujii T, Sugimoto H, Koike M, Nomoto S, Fujiwara M, Kodera Y. Epithelial to mesenchymal transition might be induced via CD44 isoform switching in colorectal cancer. J Surg Oncol. 2014; 110:745-51.

126. Bánky B, Rásó-Barnett L, Barbai T, Tímár J, Becságh P, Rásó E. Characteristics of CD44 alternative splice pattern in the course of human colorectal adenocarcinoma progression. Mol Cancer. 2012; 11:83.

127. Günthert AR, Sträter J, von Reyher U, Henne C, Joos S, Koretz K, Moldenhauer G, Krammer PH, Möller P. Early detachment of colon carcinoma cells during CD95(APO-1/ Fas)-mediated apoptosis. I. De-adhesion from hyaluronate by shedding of CD44. J Cell Biol. 1996; 134:1089-96.

128. Ayadi M, Bouygues A, Ouaret D, Ferrand N, Chouaib S, Thiery JP, Muchardt C, Sabbah M, Larsen AK. Chronic chemotherapeutic stress promotes evolution of stemness and WNT/beta-catenin signaling in colorectal cancer cells: implications for clinical use of WNT-signaling inhibitors. Oncotarget. 2015; 6:18518-33. https://doi.org/10.18632/ oncotarget.3934.

129. Akamatsu S, Yazawa S, Zenita K, Matsumoto H, Tachikawa T, Kannagi R. Elevation of an alpha(1,3)fucosyltransferase activity correlated with apoptosis in the human colon adenocarcinoma cell line, HT-29. Glycoconj J. 1996; 13:1021-9.

130. Rapoport E, Pendu JL. Glycosylation alterations of cells in late phase apoptosis from colon carcinomas. Glycobiology. 1999; 9:1337-45.

131. Yanagisawa Y, Maruta F, Iinuma N, Ishizone S, Koide $\mathrm{N}$, Nakayama J, Miyagawa S. Modified Irinotecan/5FU/ Leucovorin therapy in advanced colorectal cancer and predicting therapeutic efficacy by expression of tumor-related enzymes. Scand J Gastroenterol. 2007; 42:477-84
132. Baldini SF, Lefebvre T. O-GlcNAcylation and the Metabolic Shift in High-Proliferating Cells:All the Evidence Suggests that Sugars Dictate the Flux of Lipid Biogenesis in Tumor Processes. Front Oncol. 2016; 6:6.

133. Mi W, Gu Y, Han C, Liu H, Fan Q, Zhang X, Cong Q, Yu W. $\mathrm{O}-$ GlcNAcylation is a novel regulator of lung and colon cancer malignancy. Biochim Biophys Acta. 2011; 1812:514-9.

134. Olivier-Van Stichelen S, Guinez C, Mir AM, Perez-Cervera Y, Liu C, Michalski JC, Lefebvre T. The hexosamine biosynthetic pathway and O-GlcNAcylation drive the expression of $\beta$-catenin and cell proliferation. Am J Physiol Endocrinol Metab. 2012; 302:E417-424.

135. Steenackers A, Olivier-Van Stichelen S, Baldini SF, Dehennaut V, Toillon RA, Le Bourhis X, El YazidiBelkoura I, Lefebvre T. Silencing the Nucleocytoplasmic O-GlcNAc Transferase Reduces Proliferation, Adhesion, and Migration of Cancer and Fetal Human Colon Cell Lines. Front Endocrinol (Lausanne). 2016; 7:46.

136. Phueaouan T, Chaiyawat P, Netsirisawan P, Chokchaichamnankit D, Punyarit P, Srisomsap C, Svasti J, Champattanachai V. Aberrant O-GlcNAc-modified proteins expressed in primary colorectal cancer. Oncol Rep. 2013; 30:2929-36.

137. Hart GW, Greis KD, Dong LY, Blomberg MA, Chou TY, Jiang MS, Roquemore EP, Snow DM, Kreppel LK, Cole RN. O-linked N-acetylglucosamine:the "yin-yang" of Ser/Thr phosphorylation? Nuclear and cytoplasmic glycosylation. Adv Exp Med Biol. 1995; 376:115-23.

138. Olivier-Van Stichelen S, Dehennaut V, Buzy A, Zachayus JL, Guinez C, Mir AM, El Yazidi-Belkoura I, Copin MC, Boureme D, Loyaux D, Ferrara P, Lefebvre T. O-GlcNAcylation stabilizes $\beta$-catenin through direct competition with phosphorylation at threonine 41. FASEB J. 2014; 28:3325-38.

139. Olivier-Van Stichelen S, Drougat L, Dehennaut V, El Yazidi-Belkoura I, Guinez C, Mir AM, Michalski JC, Vercoutter-Edouart AS, Lefebvre T. Serum-stimulated cell cycle entry promotes ncOGT synthesis required for cyclin D expression. Oncogenesis. 2012; 1:e36.

140. Zhou F, Huo J, Liu Y, Liu H, Liu G, Chen Y, Chen B. Elevated glucose levels impair the $\mathrm{WNT} / \beta$-catenin pathway via the activation of the hexosamine biosynthesis pathway in endometrial cancer. J Steroid Biochem Mol Biol. 2016; 159:19-25.

141. Itkonen HM, Minner S, Guldvik IJ, Sandmann MJ, Tsourlakis MC, Berge V, Svindland A, Schlomm T, Mills IG. O-GlcNAc transferase integrates metabolic pathways to regulate the stability of c-MYC in human prostate cancer cells. Cancer Res. 2013; 73:5277-87.

142. Kamemura K, Hayes BK, Comer FI, Hart GW. Dynamic interplay between O-glycosylation and O-phosphorylation of nucleocytoplasmic proteins:alternative glycosylation/ phosphorylation of THR-58, a known mutational hot spot of c-Myc in lymphomas, is regulated by mitogens. J Biol Chem. 2002; 277:19229-35. 
143. Caldwell SA, Jackson SR, Shahriari KS, Lynch TP, Sethi G, Walker S, Vosseller K, Reginato MJ. Nutrient sensor O-GlcNAc transferase regulates breast cancer tumorigenesis through targeting of the oncogenic transcription factor FoxM1. Oncogene. 2010; 29:2831-42.

144. Yang WH, Kim JE, Nam HW, Ju JW, Kim HS, Kim YS, Cho JW. Modification of p53 with O-linked $\mathrm{N}$-acetylglucosamine regulates p53 activity and stability. Nat Cell Biol. 2006; 8:1074-83.

145. Wells L, Slawson C, Hart GW. The E2F-1 associated retinoblastoma-susceptibility gene product is modified by O-GlcNAc. Amino Acids. 2011; 40:877-83.

146. Morin PJ, Sparks AB, Korinek V, Barker N, Clevers H, Vogelstein B, Kinzler KW. Activation of beta-catenin-Tcf signaling in colon cancer by mutations in beta-catenin or APC. Science. 1997; 275:1787-90.

147. Chaiyawat P, Netsirisawan P, Svasti J, Champattanachai V. Aberrant O-GlcNAcylated Proteins:New Perspectives in Breast and Colorectal Cancer. Front Endocrinol (Lausanne). 2014; 5:193.

148. Park SY, Kim HS, Kim NH, Ji S, Cha SY, Kang JG, Ota I, Shimada K, Konishi N, Nam HW, Hong SW, Yang WH, Roth J, et al. Snaill is stabilized by O-GlcNAc modification in hyperglycaemic condition. EMBO J. 2010; 29:3787-96.

149. Guo H, Zhang B, Nairn AV, Nagy T, Moremen KW, Buckhaults P, Pierce M. O-Linked N-Acetylglucosamine (O-GlcNAc) Expression Levels Epigenetically Regulate Colon Cancer Tumorigenesis by Affecting the Cancer Stem Cell Compartment via Modulating Expression of Transcriptional Factor MYBL1. J Biol Chem. 2017; 292:4123-37.

150. Taparra K, Tran PT, Zachara NE. Hijacking the Hexosamine Biosynthetic Pathway to Promote EMT-Mediated Neoplastic Phenotypes. Front Oncol. 2016; 6.

151. Carvalho-Cruz P, Alisson-Silva F, Todeschini AR, Dias WB. Cellular glycosylation senses metabolic changes and modulates cell plasticity during epithelial to mesenchymal transition. Dev Dyn. 2017.

152. Bond MR, Hanover JA. A little sugar goes a long way:The cell biology of O-GlcNAc. J Cell Biol. 2015; 208:869-80.

153. Zachara NE, Molina H, Wong KY, Pandey A, Hart GW. The dynamic stress-induced "O-GlcNAc-ome" highlights functions for O-GlcNAc in regulating DNA damage/repair and other cellular pathways. Amino Acids. 2011; 40:793-808.

154. Zachara NE, O'Donnell N, Cheung WD, Mercer JJ, Marth JD, Hart GW. Dynamic O-GlcNAc modification of nucleocytoplasmic proteins in response to stress. A survival response of mammalian cells. J Biol Chem. 2004; 279:30133-42.

155. Ma Z, Vocadlo DJ, Vosseller K. Hyper-O-GlcNAcylation is anti-apoptotic and maintains constitutive NF- $\kappa \mathrm{B}$ activity in pancreatic cancer cells. J Biol Chem. 2013; 288:15121-30.

156. Ferrer CM, Lynch TP, Sodi VL, Falcone JN, Schwab LP, Peacock DL, Vocadlo DJ, Seagroves TN, Reginato MJ. O-GlcNAcylation regulates cancer metabolism and survival stress signaling via regulation of the HIF-1 pathway. Mol Cell. 2014; 54:820-31.

157. Godai T, Suda T, Sugano N, Tsuchida K, Shiozawa M, Sekiguchi H, Sekiyama A, Yoshihara M, Matsukuma S, Sakuma Y, Tsuchiya E, Kameda Y, Akaike M, et al. Identification of colorectal cancer patients with tumors carrying the TP53 mutation on the codon 72 proline allele that benefited most from 5-fluorouracil (5-FU) based postoperative chemotherapy. BMC Cancer. 2009; 9:420.

158. Gokare P, Finnberg NK, Abbosh PH, Dai J, Murphy ME, El-Deiry WS. P53 represses pyrimidine catabolic gene dihydropyrimidine dehydrogenase ( DPYD ) expression in response to thymidylate synthase (TS) targeting. Scientific Reports. 2017; 7:9711.

159. Wen T, Hou K, Li Z, Li L, Yu H, Liu Y, Li Y, Yin Z. Silencing $\beta$-linked $\mathrm{N}$-acetylglucosamine transferase induces apoptosis in human gastric cancer cells through PUMA and caspase-3 pathways. Oncol Rep. 2015; 34:3140-6.

160. Pepe F, Pagotto S, Soliman S, Rossi C, Lanuti P, Braconi C, Mariani-Costantini R, Visone R, Veronese A. Regulation of miR-483-3p by the O-linked $\mathrm{N}$-acetylglucosamine transferase links chemosensitivity to glucose metabolism in liver cancer cells. Oncogenesis. 2017; 6:e328.

161. Kang KA, Piao MJ, Ryu YS, Kang HK, Chang WY, Keum YS, Hyun JW. Interaction of DNA demethylase and histone methyltransferase upregulates $\mathrm{Nrf2}$ in 5-fluorouracilresistant colon cancer cells. Oncotarget. 2016; 7:40594-620. https://doi.org/10.18632/oncotarget.9745.

162. Leturcq M, Lefebvre T, Vercoutter-Edouart AS. O-GlcNAcylation and chromatin remodeling in mammals:an up-to-date overview. Biochem Soc Trans. 2017; 45:323-38.

163. Shi FT, Kim H, Lu W, He Q, Liu D, Goodell MA, Wan M, Songyang Z. Ten-eleven translocation 1 (Tet1) is regulated by O-linked $\mathrm{N}$-acetylglucosamine transferase (Ogt) for target gene repression in mouse embryonic stem cells. J Biol Chem. 2013; 288:20776-84.

164. Vella P, Scelfo A, Jammula S, Chiacchiera F, Williams K, Cuomo A, Roberto A, Christensen J, Bonaldi T, Helin K, Pasini D. Tet proteins connect the O-linked $\mathrm{N}$-acetylglucosamine transferase Ogt to chromatin in embryonic stem cells. Mol Cell. 2013; 49:645-56.

165. Gmeiner WH, Reinhold WC, Pommier Y. Genome-wide mRNA and microRNA profiling of the NCI 60 cell-line screen and comparison of FdUMP[10] with fluorouracil, floxuridine, and topoisomerase 1 poisons. Mol Cancer Ther. 2010; 9:3105-14.

166. Temmink OH, Bijnsdorp IV, Prins HJ, Losekoot N, Adema AD, Smid K, Honeywell RJ, Ylstra B, Eijk PP, Fukushima M, Peters GJ. Trifluorothymidine resistance is associated with decreased thymidine kinase and equilibrative nucleoside transporter expression or increased secretory phospholipase A2. Mol Cancer Ther. 2010; 9:1047-57.

167. Kanwal S, Fardini Y, Pagesy P, N'tumba-Byn T, PierreEugène $\mathrm{C}$, Masson $\mathrm{E}$, Hampe $\mathrm{C}$, Issad T. O-GlcNAcylationinducing treatments inhibit estrogen receptor $\alpha$ expression 
and confer resistance to 4-OH-tamoxifen in human breast cancer-derived MCF-7 cells. PLoS One. 2013; 8:e69150.

168. Haltiwanger RS, Grove K, Philipsberg GA. Modulation of O-linked $\mathrm{N}$-acetylglucosamine levels on nuclear and cytoplasmic proteins in vivo using the peptide O-GlcNAcbeta-N-acetylglucosaminidase inhibitor O-(2-acetamido-2deoxy-D-glucopyranosylidene)amino-N-phenylcarbamate. J Biol Chem. 1998; 273:3611-7.

169. Han I, Kudlow JE. Reduced O glycosylation of Sp1 is associated with increased proteasome susceptibility. Mol Cell Biol. 1997; 17:2550-8.

170. Yang X, Su K, Roos MD, Chang Q, Paterson AJ, Kudlow JE. O-linkage of $\mathrm{N}$-acetylglucosamine to $\mathrm{Sp} 1$ activation domain inhibits its transcriptional capability. Proc Natl Acad Sci USA. 2001; 98:6611-6.

171. Fraczyk T, Kubiński K, Masłyk M, Cieśla J, Hellman U, Shugar D, Rode W. Phosphorylation of thymidylate synthase from various sources by human protein kinase CK2 and its catalytic subunits. Bioorg Chem. 2010; 38:124-31.

172. Tarrant MK, Rho HS, Xie Z, Jiang YL, Gross C, Culhane JC, Yan G, Qian J, Ichikawa Y, Matsuoka T, Zachara N, Etzkorn FA, Hart GW, et al. Regulation of CK2 by phosphorylation and O-GlcNAcylation revealed by semisynthesis. Nat Chem Biol. 2012; 8:262-9.

173. Champattanachai V, Netsirisawan $P$, Chaiyawat $P$, Phueaouan $\mathrm{T}$, Charoenwattanasatien R, Chokchaichamnankit D, Punyarit P, Srisomsap C, Svasti J. Proteomic analysis and abrogated expression of O-GlcNAcylated proteins associated with primary breast cancer. Proteomics. 2013; 13:2088-99.

174. Noach N, Segev Y, Levi I, Segal S, Priel E. Modification of topoisomerase I activity by glucose and by O-GlcNAcylation of the enzyme protein. Glycobiology. 2007; 17:1357-64.

175. Jansen WJ, Zwart B, Hulscher ST, Giaccone G, Pinedo HM, Boven E. CPT-11 in human colon-cancer cell lines and xenografts:characterization of cellular sensitivity determinants. Int J Cancer. 1997; 70:335-40.

176. Peeters PJHL, Bazelier MT, Leufkens HGM, de Vries F, De Bruin ML. The risk of colorectal cancer in patients with type 2 diabetes:associations with treatment stage and obesity. Diabetes Care. 2015; 38:495-502.

177. Dignam JJ, Polite BN, Yothers G, Raich P, Colangelo L, O'Connell MJ, Wolmark N. Body mass index and outcomes in patients who receive adjuvant chemotherapy for colon cancer. J Natl Cancer Inst. 2006; 98:1647-54.

178. Meyerhardt JA, Sato K, Niedzwiecki D, Ye C, Saltz LB, Mayer RJ, Mowat RB, Whittom R, Hantel A, Benson A, Wigler DS, Venook A, Fuchs CS. Dietary glycemic load and cancer recurrence and survival in patients with stage III colon cancer:findings from CALGB 89803. J Natl Cancer Inst. 2012; 104:1702-11.

179. Stein KB, Snyder CF, Barone BB, Yeh HC, Peairs KS, Derr RL, Wolff AC, Brancati FL. Colorectal cancer outcomes, recurrence, and complications in persons with and without diabetes mellitus:a systematic review and meta-analysis. Dig Dis Sci. 2010; 55:1839-51.

180. Meyerhardt JA, Heseltine D, Niedzwiecki D, Hollis D, Saltz LB, Mayer RJ, Thomas J, Nelson H, Whittom R, Hantel A, Schilsky RL, Fuchs CS. Impact of physical activity on cancer recurrence and survival in patients with stage III colon cancer:findings from CALGB 89803. J Clin Oncol. 2006; 24:3535-41.

181. de Freitas Junior JC, Morgado-Díaz JA. The role of $\mathrm{N}$-glycans in colorectal cancer progression: potential biomarkers and therapeutic applications. Oncotarget. 2016; 7:19395-413. https://doi.org/10.18632/oncotarget.6283.

182. de Oliveira Figueirôa E, da Cunha CRA, Albuquerque PBS, de Paula RA, Aranda-Souza MÂ, da Silva MA, Zagmignan A, Carneiro-da-Cunha MG, da Silva LCN, Dos Santos Correia MT. Lectin-carbohydrate interactions:implications for the development of new anticancer agents. Curr Med Chem. 2017.

183. AlSadek DMM, Badr HA, Al-Shafie TA, El-Bahr SM, ElHouseini ME, Djansugurova LB, Li CZ, Ahmed H. Cancer cell death induced by nanomagnetolectin. Eur J Cell Biol. 2017.

184. Shi J, Kantoff PW, Wooster R, Farokhzad OC. Cancer nanomedicine:progress, challenges and opportunities. Nat Rev Cancer. 2017; 17:20-37.

185. Dube DH, Bertozzi CR. Glycans in cancer and inflammation--potential for therapeutics and diagnostics. Nat Rev Drug Discov. 2005; 4:477-88.

186. Balint JP, Gabitzsch ES, Rice A, Latchman Y, Xu Y, Messerschmidt GL, Chaudhry A, Morse MA, Jones FR. Extended evaluation of a phase 1/2 trial on dosing, safety, immunogenicity, and overall survival after immunizations with an advanced-generation Ad5 [E1-, E2b-]-CEA(6D) vaccine in late-stage colorectal cancer. Cancer Immunol Immunother. 2015; 64:977-87.

187. Duggan MC, Jochems C, Donahue RN, Richards J, Karpa V, Foust E, Paul B, Brooks T, Tridandapani S, Olencki T, Pan X, Lesinski GB, Schlom J, et al. A phase I study of recombinant (r) vaccinia-CEA(6D)-TRICOM and rFowlpox-CEA(6D)-TRICOM vaccines with GM-CSF and IFN- $\alpha-2 b$ in patients with CEA-expressing carcinomas. Cancer Immunol Immunother. 2016; 65:1353-64.

188. Morse MA, Hobeika A, Gwin W, Osada T, Gelles J, Rushing C, Niedzwiecki D, Lyerly HK. Phase I study of alphaviral vector (AVX701) in colorectal cancer patients:comparison of immune responses in stage III and stage IV patients. Journal for ImmunoTherapy of Cancer. 2015; 3:P444.

189. Nemunaitis J, Bedell C, Klucher K, Vo A, Whiting S. Phase 1 dose escalation of ONT-10, a therapeutic MUC1 vaccine, in patients with advanced cancer. Journal for ImmunoTherapy of Cancer. 2013; 1:P240. 